\title{
A model analysis of the relationship between climate perturbations and carbon budget anomalies in global terrestrial ecosystems: 1970 to 1997
}

\author{
Akihiko Ito*, Takehisa Oikawa \\ Institute of Biological Sciences, University of Tsukuba, Tennodai 1-1-1, Tsukuba, Ibaraki 305-8572, Japan
}

\begin{abstract}
We performed a model analysis of the effect of climatic perturbations from 1970 to 1997 on the carbon budget of terrestrial ecosystems at the global scale. The model, Sim-CYCLE, enabled us to simulate carbon storage in terrestrial pools and monthly carbon fluxes between the atmosphere and the biosphere, e.g. photosynthesis, respiration, decomposition, and net ecosystem production (NEP). For the global analysis, we adopted the Matthews biome distribution map (12 biome types) and the US National Centers for Environmental Prediction and the US National Center for Atmospheric Research (NCEP/ NCAR) reanalysis climate dataset, which is at a spatial resolution of T62 (5828 land cells). During the 28 yr experimental period, global NEP showed considerable climate-induced interannual anomalies ( $\triangle$ NEPs) ranging from -2.06 $\mathrm{Pg} \mathrm{C} \mathrm{yr}^{-1}$ (source) in 1983 to +2.25 (sink) $\mathrm{Pg} \mathrm{C} \mathrm{yr}^{-1}$ in 1971, being sufficiently large to give rise to anomalies in the atmospheric $\mathrm{CO}_{2}$ concentration from +0.97 to $-1.06 \mathrm{ppmv}$. Regression analyses demonstrated the following: (1) annual $\triangle$ NEPs had the highest correlation $\left(\mathrm{r}^{2}=0.38\right)$ with the temperature anomaly at the global scale; (2) the anomalies in precipitation resulted in a considerable $\triangle$ NEP in northern high and middle regions; (3) an anomalous global warming by $+1{ }^{\circ} \mathrm{C}$ brought about a negative $\Delta \mathrm{NEP}$ of $-2.7 \mathrm{Pg} \mathrm{C} \mathrm{yr}^{-1}$; (4) the responsiveness was primarily attributable to the temperature sensitivities of plant respiration and soil decomposition, and secondarily to the moisture sensitivity of decomposition; and (5) the temperature dependence of $\triangle$ NEP had a clear seasonality, i.e. most sensitive in July to September (summer in the northern hemisphere) relative to other seasons. In 1983, when an ENSO event happened and the tropical zone was anomalously hot $\left(0.4^{\circ} \mathrm{C}\right.$ above the long-

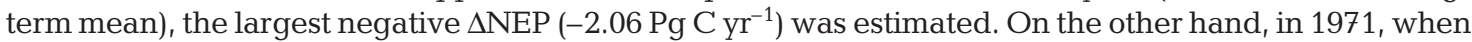
global mean temperature was relatively low $\left(0.2^{\circ} \mathrm{C}\right.$ below the long-term mean), the largest positive $\triangle \mathrm{NEP}\left(+2.25 \mathrm{Pg} \mathrm{C} \mathrm{yr}^{-1}\right)$ was estimated. Furthermore, in 1992, when an anomalous cooling during the growing period $\left(0.3^{\circ} \mathrm{C}\right.$ below the long-term mean) was caused by the Mt. Pinatubo eruption (June 1991), a considerable positive $\triangle \mathrm{NEP}\left(+1.14 \mathrm{Pg} \mathrm{C} \mathrm{yr}^{-1}\right)$ was estimated. The climate dependencies of global terrestrial ecosystems analyzed here may contain significant implications not only for the present functioning of atmosphere-biosphere carbon exchange, but also for ongoing global warming.
\end{abstract}

KEY WORDS: Carbon budget · Terrestrial ecosystem $\cdot$ Net ecosystem production (NEP) $\cdot$ Interannual change $\cdot$ Climatic perturbation $\cdot$ Model analysis

\section{INTRODUCTION}

Terrestrial ecosystems play a critical role in the global carbon cycle (Bolin et al. 1979). However, in spite of a large amount of effort, we can only roughly quantify the extent of the terrestrial ecosystem net car-

*E-mail: itoh@oak.biol.tsukuba.ac.jp bon sink, and how it will change in the future. We should take 3 major effects into account at the global scale: the ongoing $\mathrm{CO}_{2}$ enrichment, climate change, and human land-use change. Anthropogenic $\mathrm{CO}_{2}$ emission has steadily increased the atmospheric $\mathrm{CO}_{2}$ concentration since the pre-industrial revolution age; this rising concentration has exerted a monotonous, although non-linear, fertilization effect on the ecosystem carbon cycle (Melillo et al. 1996). Human land-use 
change may be the most complicated factor to predict, but qualitatively this effect has reduced and will continue to reduce carbon storage of the biosphere (Houghton et al. 1998). In comparison, the impacts of climate change on the biosphere, even their direction, are less clear for the following reasons: (1) climate influences various ecosystem processes simultaneously; (2) a number of climatic factors, such as temperature, precipitation, and irradiance, change concurrently and affect ecosystem processes interactively; (3) spatial variability of climatic anomalies is large and scale dependent; and (4) several fluctuations that have different time-scales are multiplicatively combined in the observed climate records.

In this study, we put emphasis on the effect of interannual climatic perturbations, so that we may address the environmental dependency of the atmospherebiosphere $\mathrm{CO}_{2}$ exchange. An El Niño/Southern Oscillation (ENSO) event represents the most obvious interannual climate change, and often is accompanied by regionally warmer temperatures and lower precipitation (Ropelewski \& Halpert 1987, Halpert \& Ropelewski 1992). Also, a huge volcanic eruption can lead to attenuated direct solar radiation and cooler surface temperatures (Robock \& Mao 1995). These clear perturbations may have an influence on ecosystem productivity at the broad scale, as observed by remote sensing (Myneni et al. 1997).

The short-term impact of climate change on ecosystems should be mainly regulated by a couple of physiological processes, and then we can describe the impacts with an ecophysiology-based model. Although the atmosphere-biosphere $\mathrm{CO}_{2}$ exchange is partly affected by such disturbance processes as fire and deforestation, we focus only on those processes regulated at the physiological level, such as photosynthesis, respiration, and decomposition. Other processes, in particular biomass burning, may provide a substantial contribution not only at the local scale but also at the continental scale, and they have been addressed by other studies (e.g. Wittenberg et al. 1998).

In this paper, we simulate the time-series of atmosphere-biosphere $\mathrm{CO}_{2}$ exchange for 1970 to 1997 , and analyze the relationship between the climate perturbations and the anomalies in the terrestrial carbon budget, especially in net ecosystem production $(\triangle \mathrm{NEP})$, which indicates whether an ecosystem acted as a net carbon sink or a source during a given period. Then, we discuss whether the estimated $\triangle \mathrm{NEP}$ could have an influence to such an extent that it contributed to the observed anomalies in the atmospheric $\mathrm{CO}_{2}$ concentration (Keeling et al. 1995). Indeed, this issue has attracted the attention of researchers of global carbon cycle models (e.g. Dai \& Fung 1993, Kaduk \& Heimann 1994, Maisongrande et al. 1995, Kindermann et al.
1996, Gérard et al. 1999, Potter et al. 1999, Rayner \& Law 1999). We employ a process-based carbon cycle model of terrestrial ecosystems (Sim-CYCLE) to simulate the carbon budget.

\section{CLIMATE DATASET}

The climate condition for the model analysis is derived from the reanalysis dataset produced by the US National Centers for Environmental Prediction and the US National Center for Atmospheric Research (NCEP/NCAR). This is a gridded dataset in which observation records were interpolated by the 4 -dimensional data assimilation method (Kalnay et al. 1996). At this stage, the monthly composite dataset is available for $28 \mathrm{yr}$, from January 1970 to December 1997; we took this interval to be the experimental period. In the NCEP/NCAR-reanalysis dataset, surface variables are arranged on a Gaussian grid of T62 resolution $(94 \times 192$ grid cells, latitude and longitude), which seems likely to be sufficiently fine for the purpose of global analysis; we took this resolution to be the spatial resolution of simulation in this research. The carbon budget was calculated autonomously for each of the 5828 terrestrial grid points.

The advantage of adopting the reanalysis dataset is, we postulate, due to the climatological consistency and homogeneous accuracy throughout the experimental period. In addition, the NCEP/NCAR-reanalysis dataset provides a larger number of diagnostic variables than those datasets derived from simple interpolation of observations (e.g. Leemans \& Cramer 1991, New et al. 1999). The following variables were adopted for our model analysis: surface downward shortwave radiation fluxes ( $\mathrm{SWR}$, in $\mathrm{W} \mathrm{m}^{-2}$ ); ground surface air temperature $\left(\mathrm{TG}\right.$, in ${ }^{\circ} \mathrm{C}$ ); soil temperatures at 10 and $200 \mathrm{~cm}$ depth $\left(\mathrm{TS}_{10}\right.$ and $\mathrm{TS}_{200}$, in $\left.{ }^{\circ} \mathrm{C}\right)$; potential evapotranspiration rate (PET, in $\mathrm{W} \mathrm{m}^{-2}$ ); latent heat flux (i.e. actual evapotranspiration rate, $\mathrm{AET}$, in $\mathrm{W} \mathrm{m}^{-2}$ ); and volumetric soil moisture contents at 10 and $200 \mathrm{~cm}$ depth $\left(\mathrm{SMC}_{10}\right.$ and $\mathrm{SMC}_{200}$, as a fraction). Additionally, the monthly precipitation ( $\mathrm{PR}$, in $\mathrm{mm} \mathrm{mo}^{-1}$ ), although not a model input, was used later in the regression analysis between the simulation outcome and climatic factors.

Because plant $\mathrm{CO}_{2}$ assimilation utilizes only photosynthetically active radiation (PAR; 400 to $700 \mathrm{~nm}$ ) in the spectrum of total SWR, the surface irradiance $\left(\mathrm{PAR}_{\mathrm{SFC} i} \mu \mathrm{mol}\right.$ photon $\left.\mathrm{m}^{-2} \mathrm{~s}^{-1}\right)$ is given by the following:

$$
\mathrm{PAR}_{\mathrm{SFC}}=4.2 \cdot(\mathrm{SWR} \cdot 0.45)
$$

where multipliers 4.2 and 0.45 are for unit conversion from $\mathrm{W} \mathrm{m}^{-2}$ to $\mu \mathrm{mol}$ photon $\mathrm{m}^{-2} \mathrm{~s}^{-1}$, and for extraction of the fraction of PAR, respectively (Larcher 1995). 
A climatic anomaly is defined as the difference from the 28 yr average value, and was used for linear and multiple regression analyses with the carbon flux anomalies. Before the multiple regression analysis, mutual correlations among the climatic components were checked to specify a combination of independent variables.

\section{OVERVIEW OF CARBON CYCLE MODEL}

A process-based model has been developed for simulating the carbon dynamics of terrestrial ecosystems at the global scale. The basis of the model is on the drymatter production theory established by Monsi \& Saeki (1953); Oikawa (1985) constructed a theory-based ecosystem model, which successfully retrieved growth and succession in tropical forest (Oikawa 1985), temperate forest (Oikawa 1998), and grassland (Oikawa 1995) ecosystems. In this study, the ecosystem-scale model was extended to a global-scale model, and termed Sim-CYCLE (Simulation model of Carbon cYCle in Land Ecosystems). The model conceptualizes the terrestrial carbon dynamics as a 5-compartment system (Fig. 1): foliage, stem and branch, root, litter (dead biomass), and mineral soil. The model's carbon fluxes were gross primary production (GPP), plant autotrophic respiration (AR), litterfall, translocation, and heterotrophic respiration from the decomposing soil organic matter (HR). All the carbon fluxes were calculated monthly. In terms of the carbon budget, net pri- mary production (NPP) and net ecosystem production (NEP) are critically important, because NPP (= GPP AR) represents the biological productivity supporting all ecosystem structures and functions, and NEP (= NPP $-\mathrm{HR}$ ) dictates the net balance with the atmospheric $\mathrm{CO}_{2}$. For example, NEP is positive when acting as a net sink. The ecophysiological parameters in model formulae were successfully calibrated so that the model agreed sufficiently with field observations.

The biome distribution for the global simulation was derived from the mapping by Matthews (1983), for both potential biome and cultivation intensity. In our model analysis (Table 1), the spatial resolution of the original dataset, i.e. 1-degree latitude-longitude, was adjusted to that of the NCEP/NCAR-reanalysis by resampling the grid points, and the natural biome categories, i.e. 32 original types, were simplified into 12 types. From the cultivation intensity in the dataset, we can estimate the general extent of the human landuse change, although we did not include the additional deforestation during the experimental period. In arid rangelands, including savanna, grassland, and desert (biomes 7, 8, and 11 in Table 1), calculation of $\mathrm{C}_{3}$ and $\mathrm{C}_{4}$ plants is separately carried out because of their significant differences in photosynthetic capacity and sensitivities to temperature, aridity, and $\mathrm{CO}_{2}$ conditions. The ecophysiological discrepancies between $\mathrm{C}_{3}$ and $\mathrm{C}_{4}$ species are reflected in their geographical distribution $\left(\mathrm{C}_{4}\right.$ species have larger predominance in lower and warmer latitudes), and may have notable

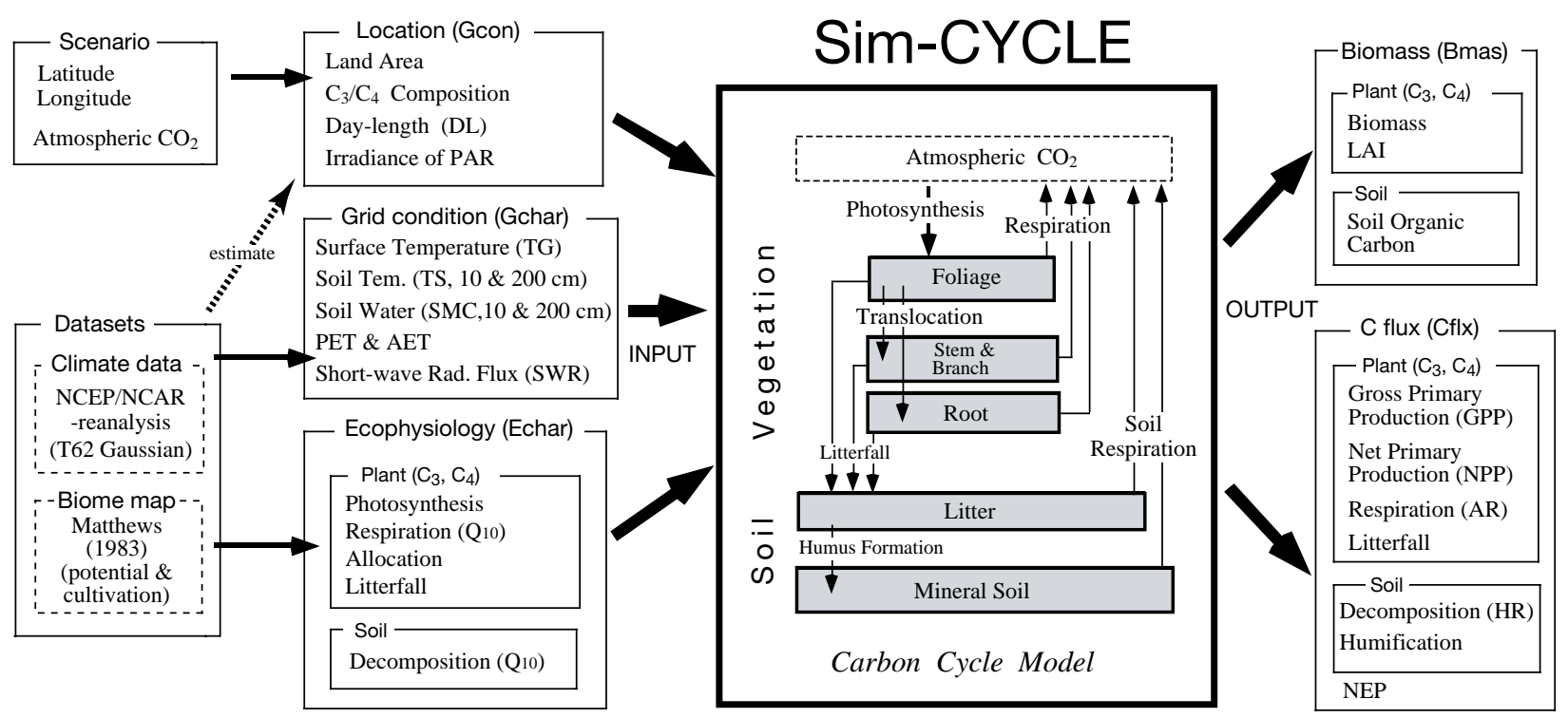

Fig. 1. Schematic of the simulation model Sim-CYCLE, in which the terrestrial carbon cycle is conceptualized by a 5-compartment system. The model, coded in the programming language C, has 3 input structures (Gcon, Gchar, and Echar) and 2 output structures (Bmas and Cflx) (the term 'structure' means assemblage of variables in C). The environmental conditions used in this paper are also shown. PAR: photosynthetically active radiation; PET, AET: potential and actual evapotranspiration rates; LAI: leaf area index; AR, HR: auto- and heterotrophic respiration 
Table 1. Biome types used for the model analysis, and their area and frequency in the T62 Gaussian grid scale. Original data are after Matthews (1983), including the potential biome and the cultivation intensity for each grid point. Areas of natural-vegetation are listed in 5 latitudinal zones (Z1 to Z5). Values in bold: the distribution center that has the largest area for each biome; underlined values: the most dominant biome for each latitudinal zone

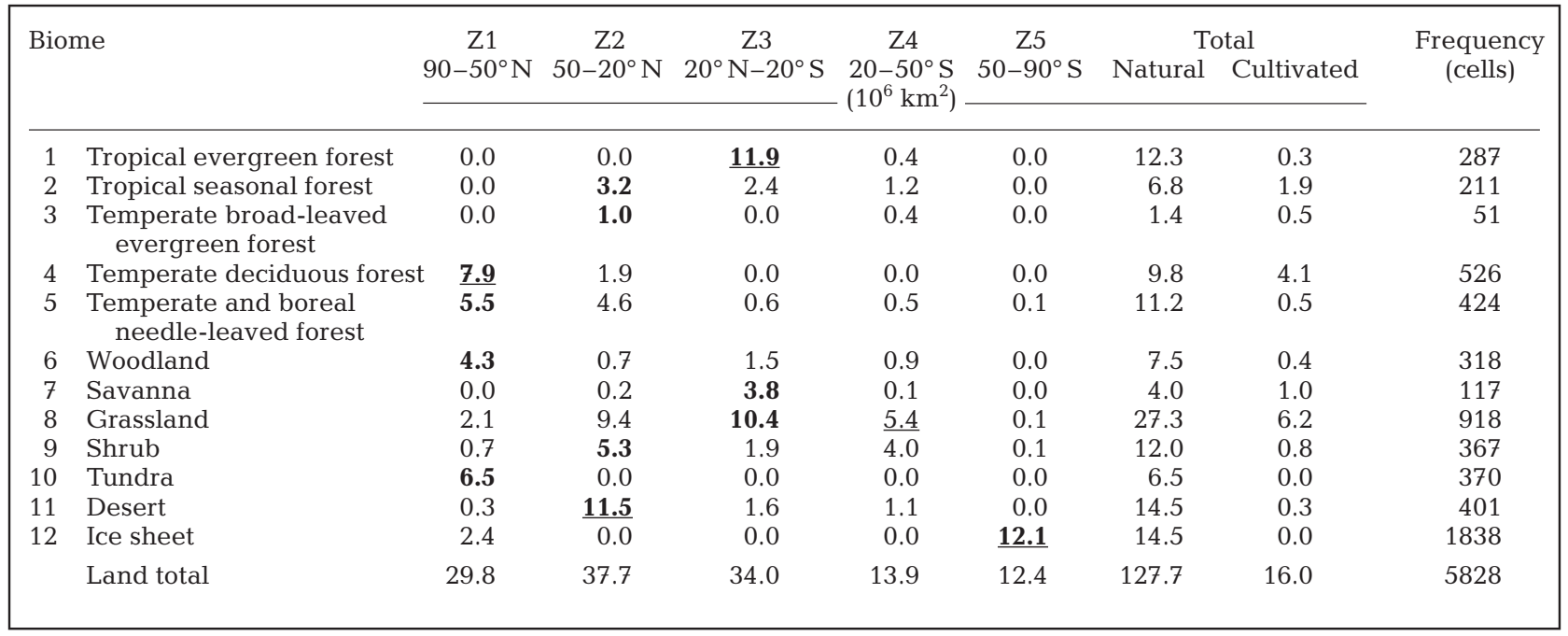

importance under global change conditions (Collatz et al. 1998). The $\mathrm{C}_{3} / \mathrm{C}_{4}$ composition in arid rangeland grids was empirically estimated by a regression model relating the composition with latitude (e.g. review by Sage et al. 1999, see also Teeri \& Stowe 1976, Ehleringer et al. 1997).

For each grid point, simulation began from a juvenile stage of the ecosystem with little carbon storage (0.1 Mg C ha ${ }^{-1}$ for each compartment), and through the iterative calculation (over $4000 \mathrm{yr}$ ) the carbon budget was to be fully stabilized so as to reach the climax stage, where annual NEP is equal to zero. In addition, in cultivated areas, a typical cultivation cycle from spring planting to autumn harvesting was modelled. The calculations were performed under a stationary atmospheric $\mathrm{CO}_{2}$ level: 325.5 ppmv, that is, the background level in 1970 (World Data Centre for Greenhouse Gases [WDCGG 1998]). Consequently, we obtained the equilibrium carbon budget both in natural and in agricultural ecosystems at the beginning of the simulation; this made it tractable to analyze the interannual change in the terrestrial carbon budget.

After that, the real simulation from 1970 to 1997 was carried out using the actual climatic and atmospheric $\mathrm{CO}_{2}$ conditions. During the experimental period, the atmospheric $\mathrm{CO}_{2}$ concentration increased at the rate of approximately $+1.4 \mathrm{ppmv} \mathrm{yr}^{-1}$, from 325.5 to 364.5 ppmv (WDCGG 1998). Note that we focused on the effect of climate perturbations, although the actual and modeled ecosystem carbon dynamics are sensitive to the atmospheric $\mathrm{CO}_{2}$ level. Exploring the effects of $\mathrm{CO}_{2}$ fertilization on the global carbon cycle remains to be done in our future research. Then, to remove the trend induced by the $\mathrm{CO}_{2}$ fertilization effect from the bulk trend (see Fig. 9A), we performed a supplementary simulation using the actual $\mathrm{CO}_{2}$ increase and the average stationary climate condition (see Fig. 9B).

$$
\begin{aligned}
& \Delta F_{\text {bulk }}=F_{\text {bulk }}-\overline{F_{\text {bulk }}} \\
& \Delta F_{\mathrm{CO}_{2}}=F_{\mathrm{CO}_{2}}-\overline{F_{\mathrm{CO}_{2}}}
\end{aligned}
$$

where $F$ represents GPP, AR, NPP, HR, or NEP. $F_{\text {bulk }}$ and $F_{\mathrm{CO}_{2}}$ denote the carbon fluxes calculated by simulations using the actual and average climate data, respectively (the line over these variables indicates the 28 yr arithmetic mean). By comparing these 2 trends, we clarified the climate-induced short-term anomalies in terrestrial carbon flux $\Delta F$ (see Fig. 9C), which takes the form:

$$
\Delta F=\Delta F_{\text {bulk }}-\Delta F_{\mathrm{CO}_{2}}
$$

Most of the analyses in this paper deal with this carbon flux anomaly.

Modelling of the environmental dependencies is a critical point for the simulation research of carbon exchange processes. Thus, Sim-CYCLE incorporates the environmental dependencies on the basis of physiological responses, i.e. at the scale of organs such as a single leaf, where a large amount of observations and experiments have been accumulated. In the next section, we present brief descriptions of carbon fluxes and their dependencies on light, temperature, and water conditions. The physiological regulation is first described, and scaling-up to the ecosystem-level regulation of the carbon budget is then covered. Several representative parameters are shown in Table 2. 
Table 2. Ecophysiological parameters in Sim-CYCLE. PC $\mathrm{MAX}$ : maximum photosynthetic rate $\left(\mu \mathrm{mol} \mathrm{CO}_{2} \mathrm{~m}^{-2} \mathrm{~s}^{-1}\right)$; $\mathrm{KA}$ light attenuation coefficient (dimensionless); $T_{\mathrm{MIN}}, T_{\mathrm{OPT}}$, and $T_{\mathrm{MAX}}$ : minimum, optimum, and maximum temperatures for photosynthesis, respectively $\left({ }^{\circ} \mathrm{C}\right) ; \mathrm{GS}_{\mathrm{MAX}}$ : maximum stomatal conductance $\left(\mu \mathrm{mol} \mathrm{CO}_{2} \mathrm{~m}^{-2} \mathrm{~s}^{-1}\right) ; \mathrm{KM}_{\mathrm{GS}}$ : coefficient of stomatal conductance $(\mu \mathrm{mol}$ $\left.\mathrm{CO}_{2} \mathrm{~m}^{-2} \mathrm{~s}^{-1}\right) ; \mathrm{SARM}_{\left(\mathrm{TG}=15^{\circ} \mathrm{C}\right)}$ : specific maintenance respiration rate for each organ at $15^{\circ} \mathrm{C}\left(\mathrm{Mg} \mathrm{C} \mathrm{Mg} \mathrm{C}-1 \mathrm{~d}^{-1}\right) ; a$ and $\mathrm{SHR}_{\left(\mathrm{TS}=15^{\circ} \mathrm{C}\right)}$ : specific heterotrophic respiration rate for each soil compartment at $15^{\circ} \mathrm{C}$ soil temperature $\left(\mathrm{Mg} \mathrm{C} \mathrm{Mg} \mathrm{C}^{-1} \mathrm{~d}^{-1}\right)$

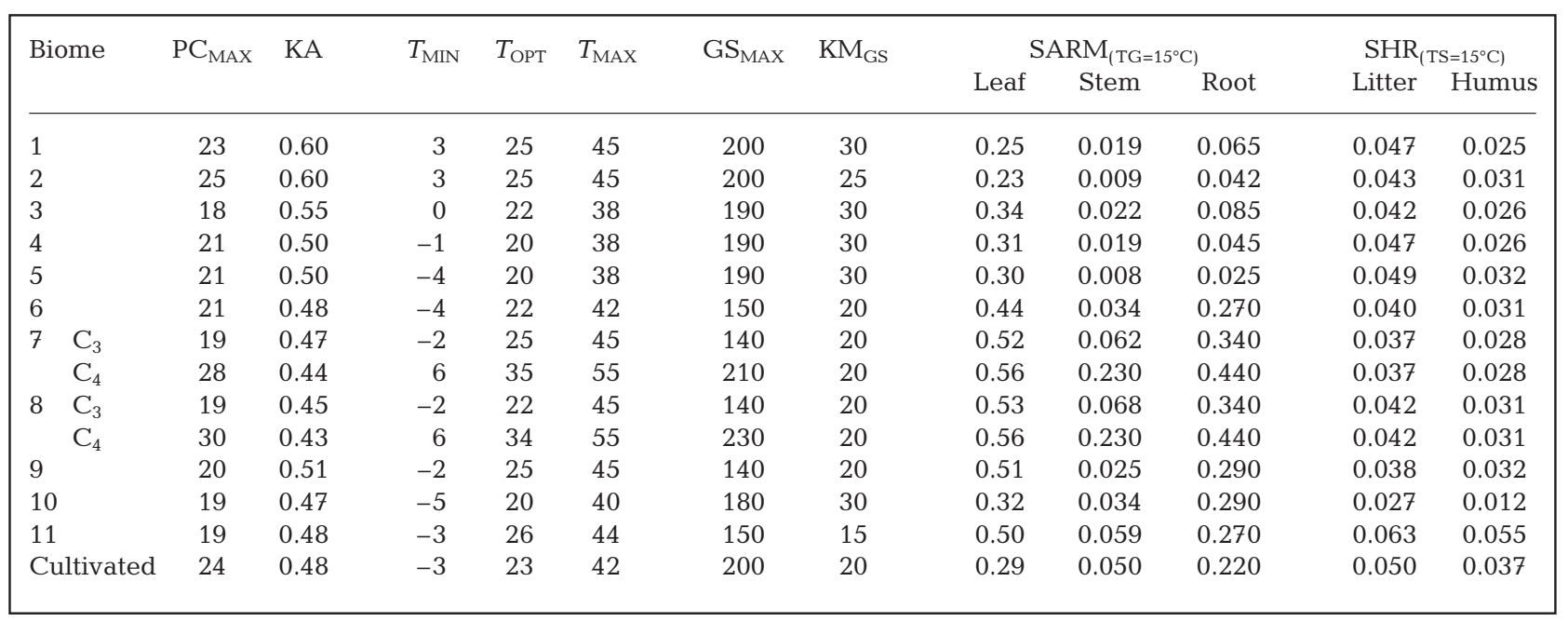

\section{ENVIRONMENTAL DEPENDENCE}

\subsection{Light conditions. 4.1.1. Single-leaf photosynthe-} sis: Photosynthesis is the sole carbon exchange process dependent directly on light condition (Fig. 2). The single-leaf photosynthetic rate $\left(\mathrm{PC}\right.$ in $\left.\mu \mathrm{mol} \mathrm{CO} \mathrm{C}^{-2} \mathrm{~s}^{-1}\right)$ is approximated by a rectangular hyperbolic equation of Michaelis-Menten type, as a function of the instantaneous irradiance $\left(\mathrm{PAR}_{\mathrm{INS}}\right.$, $\mu \mathrm{mol}$ photon $\left.\mathrm{m}^{-2} \mathrm{~s}^{-1}\right)$ :

$$
\mathrm{PC}=\frac{\mathrm{PC}_{\mathrm{SAT}} \cdot \mathrm{LUE} \cdot \mathrm{PAR}_{\mathrm{INS}}}{\mathrm{PC}_{\mathrm{SAT}}+\mathrm{LUE} \cdot \mathrm{PAR}_{\mathrm{INS}}}
$$

where $\mathrm{PC}_{\mathrm{SAT}}$ is the light-saturated photosynthetic rate, and LUE is the light-use efficiency, or quantum yield of photosynthesis. In $\mathrm{C}_{3}$ plants, the term LUE is a function of temperature and $\mathrm{CO}_{2}$ conditions $(0.04$ to $0.06 \mathrm{~mol}$ $\mathrm{CO}_{2} \mathrm{~mol}^{-1}$ photon), whereas in $\mathrm{C}_{4}$ plants it is a constant (0.055 mol CO${ }_{2} \mathrm{~mol}^{-1}$ photon) (Ehleringer \& Björkman 1977). However, for both $C_{3}$ and $C_{4}$ plants, the term $\mathrm{PC}_{\mathrm{SAT}}$ is a function of temperature and $\mathrm{CO}_{2}$ conditions, as described later. In general, $\mathrm{PC}$ of $\mathrm{C}_{3}$ plants saturates to light below $1000 \mu \mathrm{mol}$ photon $\mathrm{m}^{-2} \mathrm{~s}^{-1}$, while that of $\mathrm{C}_{4}$ plants is virtually free from light saturation. Under relatively weak irradiances, PC depends strongly on the irradiance, increasing linearly. On the other hand, during the growing period of vegetation, the daily maximum irradiance often exceeds $2000 \mu \mathrm{mol}$ photon $\mathrm{m}^{-2} \mathrm{~s}^{-1}$, and PC seems insensitive to small light fluctuations.

4.1.2 Gross photosynthetic production: The incident irradiance $\mathrm{PAR}_{\mathrm{INS}}$ decreases vertically within the canopy (Monsi \& Saeki 1953):

$$
\mathrm{PAR}_{\mathrm{INS}}=\mathrm{PAR}_{\mathrm{SFC}} \cdot \exp \left(-\mathrm{KA} \cdot \mathrm{LAI}_{\mathrm{c}}\right)
$$

where $\mathrm{PAR}_{\mathrm{SFC}}$ is the irradiance at the top of the canopy, KA is the attenuation coefficient (dimensionless) (Table 2), and $\mathrm{LAI}_{\mathrm{c}}$ is the downward cumulative leaf area index from the top of the canopy (ha ha ${ }^{-1}$ ). Furthermore, diurnal change in $\mathrm{PAR}_{\mathrm{SFC}}$ is approximated by a sine-square function:

$$
\mathrm{PAR}_{\mathrm{SFC}}=\mathrm{PAR}_{\mathrm{MD}} \cdot \sin ^{2}(\pi \cdot t / \mathrm{DL})
$$

where $\mathrm{PAR}_{\mathrm{MD}}$ is the irradiance at midday, $\mathrm{DL}$ is the daylength (h), and $t$ is the time from the dawn (h). Based on Eqs. (4) \& (5), a multiple integral of Eq. (3) for ecosystem leaf area index (LAI, derived from leaf bio-

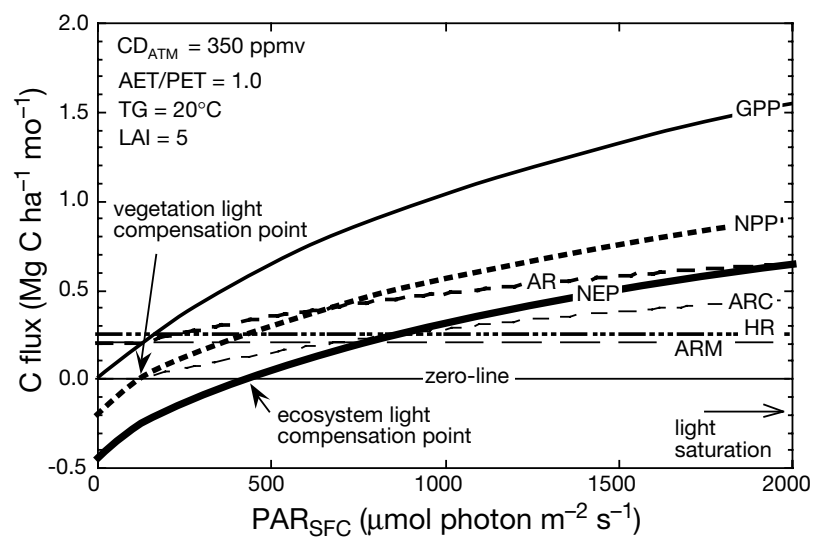

Fig. 2. Environmental responses of ecosystem carbon fluxes to irradiance of PAR $\mathrm{SFC}_{\mathrm{SF}}$ (surface PAR). GPP, NPP: gross and net primary production; NEP: net ecosystem production; ARC, ARM: construction and maintenance respiration 
mass [Mg C ha'] and specific leaf area [ha $\left.\mathrm{Mg}^{-1} \mathrm{C}\right]$ ), and daylength gives a formula evaluating daily gross photosynthetic production (GPP in $\mathrm{Mg} \mathrm{C} \mathrm{ha-1} \mathrm{d}^{-1}$ ) (Kuroiwa 1966):

$$
\begin{aligned}
\mathrm{GPP} & =\frac{2 \cdot \rho \cdot \mathrm{PC}_{\mathrm{SAT}} \cdot \mathrm{DL}}{\mathrm{KA}} \\
& \cdot \ln \frac{1+\sqrt{1+\mathrm{KA} \cdot \mathrm{LUE} \cdot \mathrm{PAR}_{\mathrm{MD}} / \mathrm{PC}_{\mathrm{SAT}}}}{1+\sqrt{1+\mathrm{KA} \cdot \mathrm{LUE} \cdot \mathrm{PAR} \mathrm{MD}_{\mathrm{MD}} \cdot \exp (-\mathrm{KA} \cdot \mathrm{LAI}) / \mathrm{PC}_{\mathrm{SAT}}}}
\end{aligned}
$$

where $\rho\left(=4.32 \times 10^{-4}\right)$ is the conversion coefficient from $\mu \mathrm{mol} \mathrm{CO}_{2} \mathrm{~m}^{-2} \mathrm{~s}^{-1}$ to $\mathrm{Mg} \mathrm{Cha} \mathrm{C}^{-1} \mathrm{~d}^{-1}$. A monthly flux ( $\mathrm{Mg} \mathrm{C} \mathrm{ha} \mathrm{Co}^{-1} \mathrm{mo}^{-1}$ is calculated simply by multiplying the daily flux by the number of days in the month.

A large number of studies which addressed the relationship between irradiance and canopy-level production show that, generally, GPP needs a much stronger irradiance for light-saturation than single-leaf photosynthesis (see review by Ruimy et al. 1995). This suggests that canopy GPP is still sensitive to $\mathrm{PAR}_{\mathrm{SFC}}$ during growing periods (Fig. 2). As well as for orbital factors, leading to seasonal and diurnal cycles, the surface irradiance may be influenced by cloudiness and atmospheric optical thickness, related to air dust and aerosol content.

4.2. Temperature condition. All of the atmospherebiosphere $\mathrm{CO}_{2}$ exchange processes are sensitive to temperature change in different fashions (Fig. 3).

4.2.1. Photosynthesis: The light-saturated leaf photosynthesis rate $\left(\mathrm{PC}_{\mathrm{SAT}} \geq 0\right)$ varies with temperature, and is approximated by a bell-shaped function of ambient temperature TG (Raich et al. 1991) relative to the rate under the optimal temperature condition $\left(\mathrm{PC}_{\mathrm{OPT}}\right)$ :

$$
\begin{aligned}
& \mathrm{PC}_{\mathrm{SAT}}(\mathrm{TG})= \\
& \frac{\left(T_{\mathrm{MAX}}-\mathrm{TG}\right)\left(T_{\mathrm{MIN}}-\mathrm{TG}\right)}{\left(T_{\mathrm{MAX}}-\mathrm{TG}\right)\left(T_{\mathrm{MIN}}-\mathrm{TG}\right)-\left(T_{\mathrm{OPT}}-\mathrm{TG}\right)^{2}} \cdot \mathrm{PC} \mathrm{OPT}_{\mathrm{OP}}
\end{aligned}
$$

where $T_{\mathrm{MAX}}, T_{\mathrm{MIN}}$, and $T_{\mathrm{OPT}}$ are the maximum, minimum, and optimum temperature $\left({ }^{\circ} \mathrm{C}\right)$ for photosynthesis, respectively (Table 2). The LUE of $\mathrm{C}_{3}$ plants is also a function of temperature (Ehleringer \& Björkman 1977), given by the following expression:

$$
\operatorname{LUE}(\mathrm{TG})=\mathrm{LUE}_{0} \cdot \frac{52-\mathrm{TG}}{3.5+0.75(52-\mathrm{TG})}
$$

where $\mathrm{LUE}_{0}$ is the constant value $\left(=0.055 \mathrm{~mol} \mathrm{CO}_{2} \mathrm{~mol}^{-1}\right.$ photon). $\mathrm{C}_{3}$ plants reduce their light-use efficiency with increasing temperature because of increased photorespiration, while $\mathrm{C}_{4}$ plants are insensitive to temperature change. After upscaling to the canopy, or the temperature-GPP relationship (Fig. 3), it follows that the GPP is markedly insensitive to temperature fluctuation around $T_{\mathrm{OPT}}$, but falls steeply near $T_{\mathrm{MIN}}$ and $T_{\mathrm{MAX}}$. Temperature anomalies around the upper and lower temperature

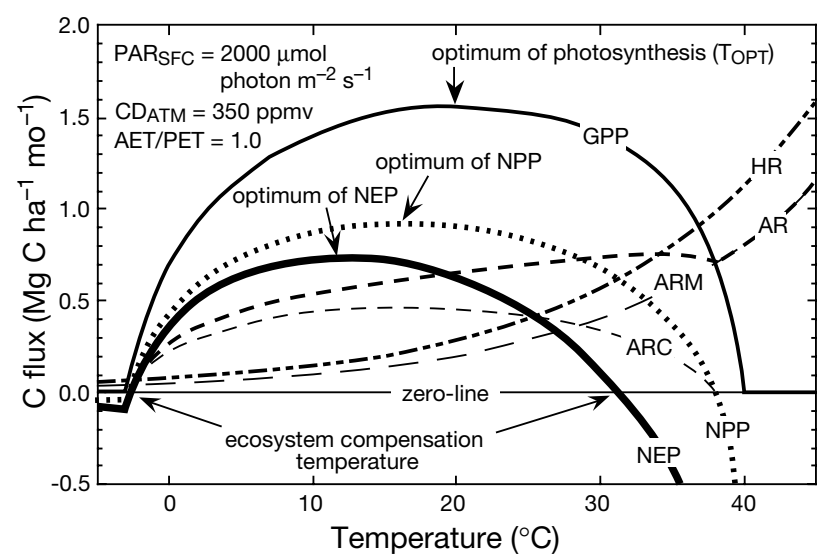

Fig. 3. Environmental responses of ecosystem carbon fluxes to temperature (TG for plant and TS for soil)

edges are important for another reason, that is, a warmer spring or autumn results in a longer growing-period, and cooler ones in a shorter growing period.

4.2.2. Plant autotrophic respiration: AR consists of 2 functional elements, the construction respiration (ARC) and the maintenance respiration (ARM). The term ARM is the cost to support a plant body and is proportional to biomass; its specific coefficient (SARM, in $\mathrm{Mg} \mathrm{C} \mathrm{Mg}^{-1} \mathrm{C} \mathrm{d}^{-1}$ ) is an explicit function of temperature (control temperature $15^{\circ} \mathrm{C}$ ):

$$
\begin{aligned}
& \operatorname{SARM}(\mathrm{TG})= \\
& \operatorname{SARM}_{\left(\mathrm{TG}-15^{\circ} \mathrm{C}\right)} \cdot \exp \left(\frac{\ln \left(Q_{10, \mathrm{ARM}}\right)}{10}(\mathrm{TG}-15)\right)
\end{aligned}
$$

where $Q_{10, \mathrm{ARM}}$ is the coefficient of temperature sensitivity, whose typical value is 2.0 (Ryan 1991). Thus, the rate AR respiration is directly and indirectly dependent on temperature, and generally increases when temperature rises. On the other hand, the term ARC is the cost of synthesizing new biomass and is proportional to the rate of growth; but, its specific coefficient (i.e. cost per unit biomass growth) is independent of environmental conditions (Amthor 1994). Note that the term ARC is related to the biomass growth rate, which is largely driven by GPP and is implicitly influenced by such environmental factors as irradiance, water availability, and ambient $\mathrm{CO}_{2}$ level (see the correspondence between GPP and ARC in Fig. 3).

4.2.3. Soil decomposition: In spite of the paucity of information, HR is the crucial component in calculating NEP. The specific rate SHR is also an exponential function of soil temperature ( $\mathrm{TS}$ in ${ }^{\circ} \mathrm{C}$ ):

$$
\operatorname{SHR}(T S)=\operatorname{SHR}_{\left(\mathrm{TS}=15^{\circ} \mathrm{C}\right)} \cdot \exp \left(\frac{\ln \left(Q_{10, \mathrm{HR}}\right)}{10}\right)(\mathrm{TS}-15)
$$

where $\mathrm{TS}$ is $\mathrm{TS}_{10}$ for the upper litter and $\mathrm{TS}_{200}$ for the lower mineral soil. The temperature sensitivity is 
represented by the coefficient $Q_{10, \mathrm{HR}}$ (Raich \& Schlesinger 1992).

4.2.4. NPP and NEP: The sensitivity of NPP and NEP at the ecosystem level can be deduced from those of GPP, AR, and HR (Fig. 3). Fitter \& Hay (1981) showed that the temperature NPP relationship is well described by a bell-shaped curve whose optimum temperature is lower than that of the temperature-GPP relationship ( $T_{\mathrm{OPT}}$ of Eq. 7). The temperature-NEP relationship is also well described by a bell-shaped curve with an even lower optimum temperature than the NPP one. Actually, a warmer temperature accelerates evapotranspiration and reduces soil water content, and it may consequently affect plant production and soil decomposition (described next). This complexity resulting from the water-temperature interaction gives an additional motivation to adopt a process-based model, rather than an empirical model.

4.3. Water and $\mathbf{C O}_{2}$ conditions. All of the atmosphere-biosphere $\mathrm{CO}_{2}$ exchange processes are directly and indirectly sensitive to habitat water conditions, and many ecosystems suffer from chronic or periodic water deficit.

4.3.1. Photosynthesis: We assume that water availability primarily regulates the aperture of leaf stomata, through which plants exchange $\mathrm{CO}_{2}$ and water simultaneously (Jones 1992). An empirical indicator, the ratio AET/PET, is derived directly from the NCEP/ NCAR-reanalysis dataset. For example, as shown in Fig. 4, if the AET/PET ratio is nearly zero under a dry condition, leaf stomatal conductance (GS, in $\mathrm{mmol} \mathrm{CO}_{2}$ $\mathrm{m}^{-2} \mathrm{~s}^{-1}$ ) is minimized so that plants do not lose water by transpiration. In contrast, if the AET/PET ratio is nearly unity, the soil is sufficiently wet and plants maximize stomatal conductance and $\mathrm{CO}_{2}$ uptake. Under intermediate moisture conditions, stomatal aperture is esti-

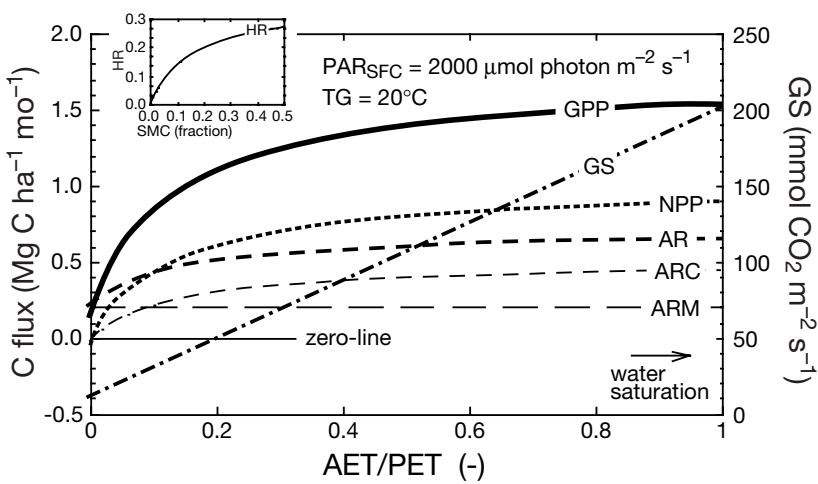

Fig. 4. Environmental responses of ecosystem carbon fluxes to water conditions represented by AET/PET ratio (inset, HR in relation to soil moisture content, SMC). For the water conditions, NEP is not shown, because NPP and HR depend on different water availability indices, and instead water dependence of leaf stomatal conductance (GS) is added mated by linear interpolation between the maximum $(\mathrm{AET} / \mathrm{PET}=1)$ and minimum $(\mathrm{AET} / \mathrm{PET}=0)$ stomatal conductances (see Table 2 for $\mathrm{GS}_{\mathrm{MAX}}$ ). GS affects the intercellular $\mathrm{CO}_{2}$ concentration $\left(\mathrm{CD}_{\mathrm{ICL}}\right.$, in ppmv), estimated as follows:

$$
\mathrm{CD}_{\mathrm{ICL}}=\frac{\mathrm{GS}}{\mathrm{KM}_{\mathrm{GS}}+\mathrm{GS}} \mathrm{CD}_{\mathrm{ATM}}
$$

where $\mathrm{KM}_{\mathrm{GS}}$ is the coefficient of stomatal conductance $\left(\mathrm{mmol} \mathrm{CO} \mathrm{m}^{-2} \mathrm{~s}^{-1}\right)$, and $\mathrm{CD}_{\mathrm{ATM}}$ is the atmospheric $\mathrm{CO}_{2}$ concentration (ppmv). Eq. (11) shows how the atmospheric $\mathrm{CO}_{2}$ concentration exerts a fertilization effect on plant photosynthesis. Finally, $\mathrm{PC}_{\mathrm{SAT}}$ is parameterized as a function of $\mathrm{CD}_{\mathrm{ICL}}$ :

$$
\mathrm{PC}_{\mathrm{SAT}}\left(\mathrm{CD}_{\mathrm{ICL}}\right)=\frac{\mathrm{CD}_{\mathrm{ICL}}}{\mathrm{KM}_{\mathrm{CD}}+\mathrm{CD}_{\mathrm{ICL}}} \mathrm{PC}_{\mathrm{MAX}}
$$

where $\mathrm{PC}_{\mathrm{MAX}}$ is the photosynthetic rate under $\mathrm{CO}_{2}$ saturation. The term $\mathrm{KM}_{\mathrm{CD}}$ (ppmv) is the coefficient of $\mathrm{CD}_{\mathrm{INC}}$ and represents the magnitude of the fertilization effect on photosynthetic rate. $\mathrm{C}_{4}$ plants which are relatively insensitive to ambient $\mathrm{CO}_{2}$ concentration have a low $\mathrm{KM}_{\mathrm{CD}}$ value, whereas $\mathrm{C}_{3}$ plants which augment productivity with increasing $\mathrm{CO}_{2}$ level have a moderate to high one (Poorter 1993, Wullschleger 1995, Curtis \& Wang 1998). Furthermore, intercellular $\mathrm{CO}_{2}$ concentration affects the LUE of $\mathrm{C}_{3}$ plants:

$$
\operatorname{LUE}\left(\mathrm{CD}_{\mathrm{ICL}}\right)=\mathrm{LUE}_{0} \frac{\mathrm{CD}_{\mathrm{ICL}}}{90+0.6 \cdot \mathrm{CD}_{\mathrm{ICL}}}
$$

Water availability affects the single-leaf photosynthetic rate, and the regulation is applicable to canopy scale GPP; the more water is available, the more carbon is assimilated as dry matter (Fig. 4).

4.3.2. Autotrophic respiration: While ARM is independent of water availability, the growth-related component ARC increases with increasing GPP and, thus, with increasing water availability (Fig. 4).

4.3.3. Decomposition: HR (Fig. 4 inset) increases with increasing the volumetric soil water content $\left(\mathrm{SMC}_{10}\right.$ and $\left.\mathrm{SMC}_{200}\right)$ (Witkamp 1966, Meentemeyer 1984):

$$
\mathrm{SHR}(\mathrm{SMC})=\mathrm{SHR}_{\mathrm{SAT}} \cdot \frac{\mathrm{SMC}}{\mathrm{KM}_{\mathrm{SMC}}+\mathrm{SMC}}
$$

where SHR is the specific decomposition rate ( $\mathrm{Mg} \mathrm{C}$ $\left.\mathrm{Mg}^{-1} \mathrm{C} \mathrm{d}^{-1}\right), \mathrm{SHR}_{\mathrm{SAT}}$ is the SHR value under water saturation, and $\mathrm{KM}_{\mathrm{SMC}}$ is the half-saturation coefficient of $\mathrm{SMC}$ (fraction). We expect that the model not accounting for the inhibition of decomposition under anaerobic conditions may be applicable to the monthly-step simulation.

4.3.4. NPP and NEP: As shown by Lieth (1975) on the ecosystem level, the annual precipitation-NPP relationship may be well described by a saturation curve 
from desert to rain forest. At the physiological level, the water- $C D_{\text {ICL }}$ and $C D_{\text {ICL }}-P C$ relationships formulated as hyperbolic functions (Eqs. 11 \& 12) imply that the water-NPP relationship is well described by a saturation curve (Fig. 4). However, an enhanced GPP leads to higher $\mathrm{ARC}$, and offsets a part of the NPP increase, while ARM is independent of water conditions. Here, we should also take into account the temperaturewater interaction, that is, a warmer temperature usually results in greater PET, but not usually in greater AET. Under certain conditions, even if temperature is below the optimum for production, a warmer temperature may aggravate water stress (i.e. smaller AET/PET ratio, GS, and $\mathrm{CD}_{\mathrm{ICL}}$ ) and decrease GPP and NPP.

In consequence, both the water-NPP and water-HR relationships show a hyperbolic-type dependence, and then the water-NEP relationship is not intuitive, because it is the net balance of NPP and HR offsetting each other. Although precipitation is one of the most changeable factors at the seasonal and interannual scales, causing local droughts and floods, a large water pool in groundwater and plant biomass often ameliorates the perturbation of water availability. On the other hand, an anomalously excess precipitation will persist in SWC for the next few months (Manabe \& Wetherald 1987). The history effect is a characteristic of the water conditions, making it difficult to estimate the impact of its fluctuation on carbon budget.

4.4. Growth process. In Sim-CYCLE, plant growth rate is strongly controlled by environmental conditions, while partitioning ratio of photosynthate among the plant compartments is assumed to be independent of environment. The dry-matter production theory (Monsi 1960) proposed a plant growth scheme from photosynthesis to reproduction: (1) dead biomass by senescence and herbivory is abandoned from plant body to soil litter, (2) ARM is initially extracted from GPP, (3) the residual photosynthate is partitioned in given ratios among compartments, reflecting the morphological features of plant life forms, and (4) ARC is extracted from each compartment, unless ARM is larger than GPP. A variation of partitioning ratio with proceeding plant growth stage was not necessary for the present purpose, because we were investigating the ecosystem carbon budget after a climax stage was reached.

The seasonality of litterfall characterizes the phenological cycle of biomes, except for evergreen forests (biomes 1, 3, 5, and 6), which have no seasonal change in leaf mortality. The growing period of evergreen forests is determined by the GPP responses to PAR and TG (see Figs. 2 \& 3). In deciduous forests, the phenological cycle is prescribed from budbreak to leaf shedding: rainy months in tropical seasonal forests (biome 2), and warm months in temperate deciduous forests (biome 4), e.g. April to October in the northern hemisphere. In the leaf-shedding month, all leaves are abandoned, and in the budbreak month, new foliage system is constructed at the cost of carbon in the stem and root compartments (reallocation). The phenological cycle of grasslands (biomes 7 and 8) is similar to that of deciduous forests, but using mostly root carbon storage in the shoot emergence month. The phenological cycle of croplands is also prescribed, e.g. from cropping in April to harvesting in October in the northern hemisphere. Accompanied with the crop harvest, a part of the aboveground and all of the underground plant biomass is supplied to the litter compartment as detritus.

\section{RESULTS}

The equilibrium carbon budget is described in Section 5.1, and then interannual change during the $28 \mathrm{yr}$, accounting for the sensitivity to $Q_{10}$ values, is illustrated in Section 5.2. In Sections 5.3 and 5.4, carbon budget anomalies are statistically related to climatic anomalies through the $28 \mathrm{yr}$. To facilitate discussion, the grid-based estimations are conveniently grouped into 5 latitudinal zones and 12 biome types. Finally, typical features of the carbon anomaly are exemplified in Section 5.5.

\subsection{Average global carbon budget}

After reaching an equilibrium through the preliminary iterative calculation, global annual GPP, AR, NPP, and HR were estimated to be 123.5, 60.5, 63.0, and $58.3 \mathrm{Pg} \mathrm{C} \mathrm{yr}^{-1}$, respectively. The crop harvest of 3.3 $\mathrm{Pg} \mathrm{C} \mathrm{yr}^{-1}$ and net sequestration of $1.4 \mathrm{Pg} \mathrm{C} \mathrm{yr}^{-1}$ accounted for the equilibrium state of carbon budget. The estimation of NPP is adequately comparable with those of other models; Cramer et al. (1997) showed that 16 other models estimated NPP to be between 40 and $70 \mathrm{Pg} \mathrm{C} \mathrm{yr}^{-1}$. As shown in Fig. 5A, the seasonal change and latitudinal distribution of NPP are also properly retrieved. The global monthly NPP oscillated from 3.3 $\mathrm{Pg} \mathrm{C} \mathrm{mo}^{-1}$ in April to $7.7 \mathrm{Pg} \mathrm{C} \mathrm{mo}^{-1}$ in July, the seasonality being mainly due to northern high latitudes. Global monthly NEP (figure not shown) was positive, i.e. uptaking carbon, during the northern growing period (1.7 to $2.2 \mathrm{Pg} \mathrm{C} \mathrm{mo}^{-1}$ ), as reflected in the seasonal cycle of the atmospheric $\mathrm{CO}_{2}$ concentration (e.g. Kohlmaier et al. 1987). Carbon pools in vegetation and soil organic matter were estimated as 545.2 and 1549.6 Pg C, respectively (Fig. 5B). From Table 3, we can see that the variation of carbon budget among the biomes is consistent with observations (e.g. Whittaker 

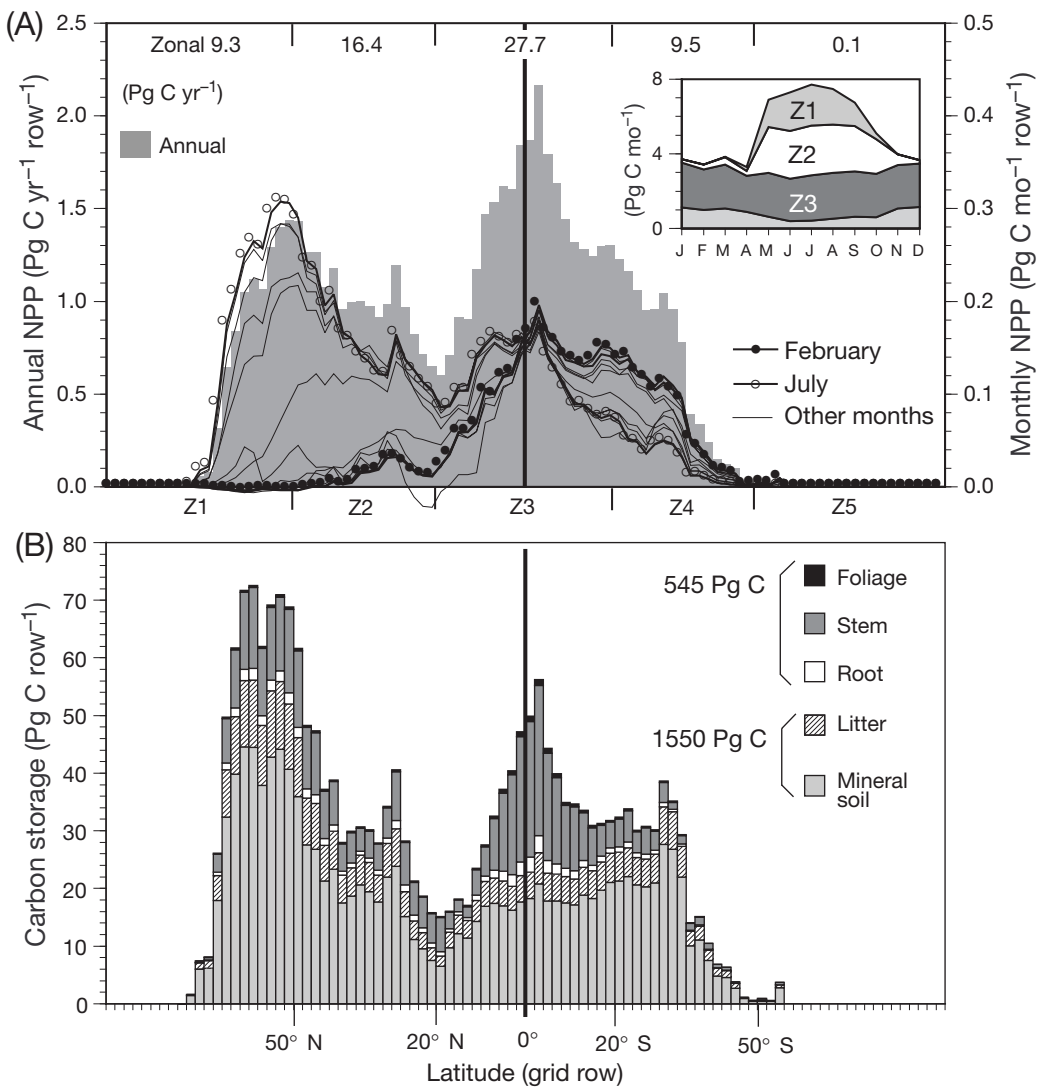

Fig. 5. Latitudinal distributions of estimated productivity and carbon storage at the equilibrium state, for each of 94 grid rows at the T62 resolution. (A) Annual and monthly NPP, in which seasonal change is emphasized by comparing values of July and February. Inset: monthly zonal NPP. (B) Carbon storage in each of the 5 compartments

1975), from tropical rain forest (biome 1), which is productive (NPP: $11.0 \mathrm{Mg} \mathrm{C} \mathrm{ha}^{-1} \mathrm{yr}^{-1}$ ) and in which carbon is abundant (C storage: $321.4 \mathrm{Mg} \mathrm{C}^{-1} \mathrm{~h}^{-1}$, to desert (biome 11) which is the most infertile (NPP: $0.2 \mathrm{Mg} \mathrm{C} \mathrm{ha}^{-1} \mathrm{yr}^{-1}$ ) and in which carbon is scarce (C storage: $3.7 \mathrm{Mg} \mathrm{C}$ $\mathrm{ha}^{-1}$.

\subsection{Time-series of global carbon anomalies}

In the NCEP/NCAR-reanalysis dataset from 1970 to 1997 (Fig. 6), there were warmer periods such as 1990-1991 and cooler periods such as 1975-1976, and periods with high or low precipitation. The ENSO events and volcanic eruptions, both of which could cause climatic perturbations, are also shown in Fig. 6, but we could not relate the global climate anomalies with these occurrences. In particular regions, however, they exerted notable effects on climate conditions and terrestrial carbon budget (see Section 5.5).

Fig. 7 shows the time-series of monthly carbon flux anomalies. Fig. 8 shows the time-series of monthly $\triangle \mathrm{NEP}$, in comparison with the estimation by Keeling et al. (1995) (see Section 6). We can see from them that considerable positive $\triangle$ NEPs occurred in 1971 and 1992, and a negative $\triangle$ NEP occurred in 1983. Interestingly, the continuous anomalies in $\Delta \mathrm{AR}$ and $\Delta$ HR for several consecutive months led to large cumulative $\triangle$ NEPs. For example, the cumulative positive $\triangle$ NEP from October 1970 to April 1972 amounts to

Table 3. Average (with standard deviation) climatic conditions and estimated carbon budget for each biome. TG: annual mean surface temperature $\left({ }^{\circ} \mathrm{C}\right)$; PR: annual precipitation $\left(\mathrm{mm} \mathrm{yr}^{-1}\right)$; SWR: annual mean short-wave radiation $\left(\mathrm{W} \mathrm{m}^{-2}\right)$; $\mathrm{NPP}$ : estimated annual net primary production $\left(\mathrm{Mg} \mathrm{C} \mathrm{ha}^{-1} \mathrm{yr}^{-1}\right)$; and $\mathrm{C}$ mass: ecosystem carbon storage $\left(\mathrm{Mg} \mathrm{C}^{-1}\right)$. The latitudinal zone in which each biome is mainly distributed is given in parenthesis

\begin{tabular}{|c|c|c|c|c|c|c|c|c|c|c|}
\hline \multirow{2}{*}{ Biome } & \multirow[b]{2}{*}{ TG } & \multirow[b]{2}{*}{$\mathrm{SD}$} & \multicolumn{4}{|c|}{ Climatic conditions } & \multirow{2}{*}{ NPP } & \multirow{2}{*}{$\mathrm{SD}$} & \multirow{2}{*}{$\mathrm{C}$ mass } & \multirow{2}{*}{ SD } \\
\hline & & & PR & $\mathrm{SD}$ & SWR & $\mathrm{SD}$ & & & & \\
\hline $1(\mathrm{Z} 3)$ & 23.1 & 2.6 & 2489 & 1032 & 223 & 19 & 11.0 & 1.1 & 321 & 85 \\
\hline 2 (Z2) & 20.7 & 5.6 & 1683 & 757 & 240 & 18 & 7.7 & 1.0 & 235 & 66 \\
\hline 3 (Z2) & 14.1 & 3.4 & 1443 & 695 & 211 & 19 & 8.0 & 2.5 & 328 & 116 \\
\hline $4 \quad(\mathrm{Z} 1)$ & 6.3 & 9.4 & 821 & 375 & 170 & 26 & 6.5 & 2.9 & 314 & 158 \\
\hline $5 \quad(\mathrm{Z} 1)$ & -0.2 & 3.8 & 721 & 250 & 199 & 34 & 5.5 & 1.7 & 346 & 99 \\
\hline $6 \quad(\mathrm{Z} 1)$ & 4.1 & 15.1 & 782 & 580 & 195 & 54 & 3.3 & 4.2 & 102 & 143 \\
\hline 7 (Z3) & 22.4 & 2.5 & 1006 & 506 & 263 & 15 & 6.0 & 1.9 & 134 & 56 \\
\hline 8 (Z3) & 14.9 & 10.4 & 721 & 677 & 246 & 35 & 4.4 & 3.4 & 104 & 86 \\
\hline 9 (Z2) & 15.2 & 8.7 & 300 & 415 & 252 & 36 & 3.8 & 3.8 & 144 & 152 \\
\hline 10 (Z1) & -9.9 & 4.8 & 365 & 212 & 146 & 12 & 1.2 & 2.1 & 147 & 228 \\
\hline 11 (Z2) & 18.8 & 11.2 & 71 & 125 & 287 & 30 & 0.2 & 0.6 & 4 & 13 \\
\hline 12 (Z5) & -34.6 & 13.0 & 147 & 240 & 158 & 10 & 0.0 & 0.0 & 0 & 0 \\
\hline Cultivated & 14.3 & 8.0 & 904 & 614 & 229 & 32 & 4.9 & 1.1 & 74 & 35 \\
\hline
\end{tabular}



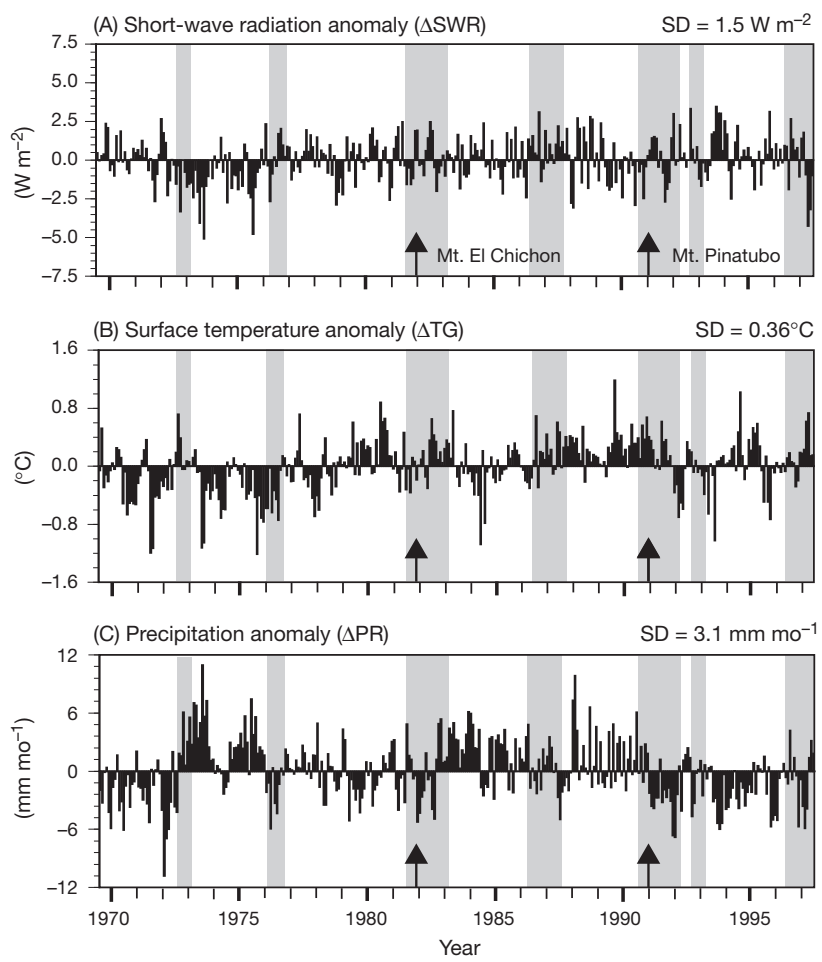

Fig. 6. Anomalies in the global average monthly climate components at the ground surface: (A) irradiance of short-wave radiation $(\Delta \mathrm{SWR})$, (B) surface temperature $(\Delta \mathrm{TG})$, and $(\mathrm{C})$ precipitation $(\triangle \mathrm{PR})$, based on the NCEP/NCAR-reanalysis dataset. Each anomaly is defined as the difference from the $28 \mathrm{yr}$ average. Shaded zones show when ENSO events occurred; arrows indicate extremely large volcanic eruptions, i.e. Mt. El Chichon in 1982 and Mt. Pinatubo in 1991

+3.80 Pg C, and the negative one from September 1982 to March 1984 amounts to $-2.66 \mathrm{Pg}$ C. The estimated time-series of annual NEP deviations using the actual and the average climates are shown in Fig. 9A,B (see Eqs. 2a,b), as well as the net anomaly $\triangle$ NEP in Fig. 9C. In addition to Fig. 9C using the standard $Q_{10}$ value of 2.0 for ARM and HR, anomalies using different $Q_{10}$ values, i.e. 1.5 and 2.5, are shown in Fig. 10, because we are aware of their importance for respiration in evaluating the carbon budget anomaly. With a $Q_{10}$ of 2.0, the global $\triangle$ NEP fluctuated from $-2.06 \mathrm{Pg} \mathrm{C} \mathrm{yr}^{-1}$ in 1983 to $+2.25 \mathrm{Pg} \mathrm{C} \mathrm{yr}^{-1}$ in $1971\left(\mathrm{SD}=1.05 \mathrm{Pg} \mathrm{C} \mathrm{yr}^{-1}\right)$, enough to have caused the observed atmospheric $\mathrm{CO}_{2}$ anomalies. It was found, however, that a larger $Q_{10}$ led to larger $\triangle \mathrm{NEPs}$, as represented by the magnitude of standard deviation (from $0.84 \mathrm{Pg} \mathrm{C} \mathrm{yr}^{-1}$ of $Q_{10}=1.5$ to 1.15 $\mathrm{Pg} \mathrm{C} \mathrm{yr}{ }^{-1}$ of $\left.Q_{10}=2.5\right)$. Moreover, in some years, the different $Q_{10}$ values led to opposite anomaly tendencies: e.g. in 1974 , a positive $\triangle$ NEP was estimated by $Q_{10}$ of 2.0 and 2.5 (Figs. 9C \& 10B), but a negative one by $Q_{10}$ of 1.5 (Fig. 10A). Another interesting aspect in Fig. 9 is that the $28 \mathrm{yr}$ average $\triangle \mathrm{NEP}$ was estimated as
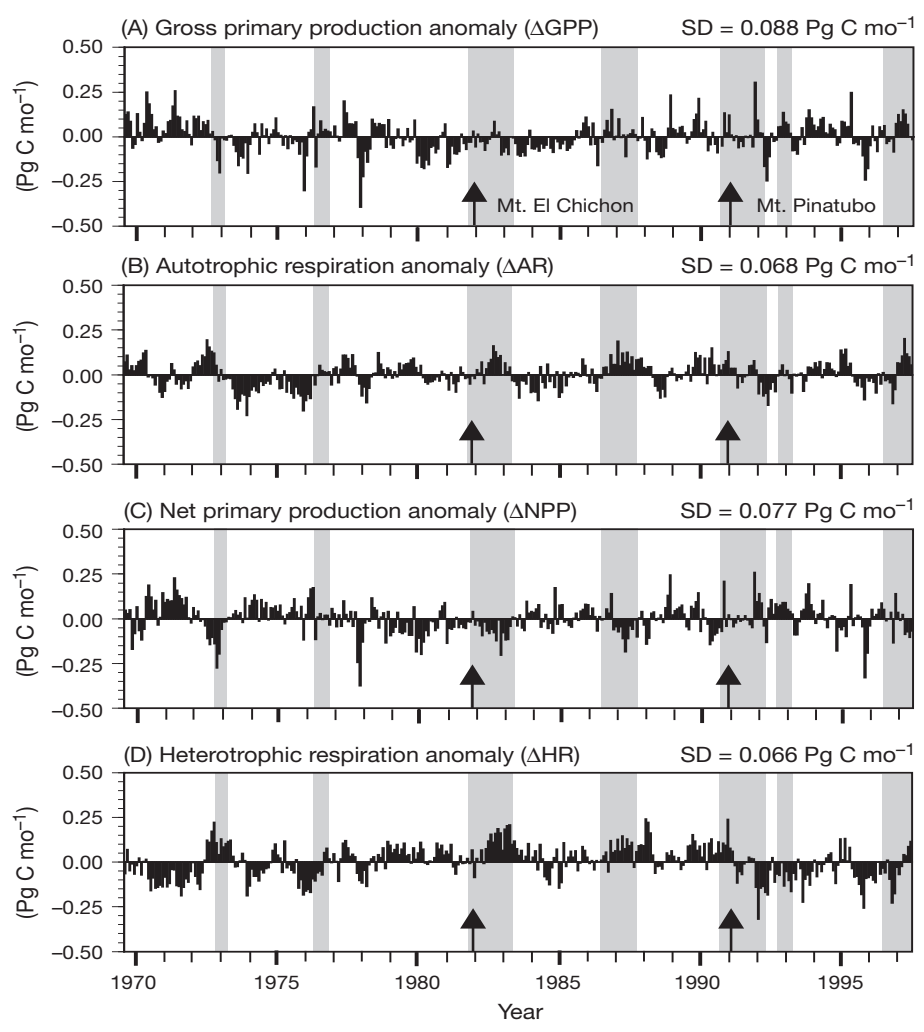

Fig. 7. Anomalies in estimated monthly carbon fluxes: (A) gross primary production $(\triangle \mathrm{GPP}),(\mathrm{B})$ plant autotrophic respiration $(\triangle \mathrm{AR}),(\mathrm{C})$ net primary production $(\triangle \mathrm{NPP})$, and (D) soil heterotrophic respiration $(\Delta \mathrm{HR})$. Shaded zones and arrows show ENSO events and extremely large volcanic eruptions, respectively. $Q_{10}$ value of 2.0 was adopted for $\Delta \mathrm{AR}$ and $\Delta \mathrm{HR}$

a positive value (Fig. 9A, +1.35 $\mathrm{Pg} \mathrm{C}^{-1}$ ), implying a net carbon sequestration into the biosphere. This enhancement was obviously due to the $\mathrm{CO}_{2}$ fertilization effect induced by the atmospheric $\mathrm{CO}_{2}$ rise from 325.5 ppmv in 1970 to 364.5 ppmv in 1997.

Table 4 summarizes the specific contributions to the global $\triangle$ NEP trend by each of the carbon fluxes and values of $\triangle \mathrm{NEP}$ for each of the 4 latitudinal zones (see Table 1, Fig. 5). Apparently, in the years when the biosphere had large $\triangle$ NEP (1) both plant and soil, i.e. $\triangle \mathrm{NPP}$ and $\triangle \mathrm{HR}$, acted as net carbon sources and (2) all zones performed similarly either as sinks (e.g. 1971 and 1992) or as sources (e.g. 1973, 1983, and 1988). However, quantitatively and often qualitatively, zonal $\triangle$ NEP occurred heterogeneously rather than homogeneously across the biosphere. We can see from Table 4 that the zone with the most influence on the global $\triangle$ NEP trend was Z3 (i.e. tropics), which is mainly occupied by such ecologically and biogeochemically active biomes as tropical rain forest (biome 1) and which is responsible for nearly half $(27.7 \mathrm{Pg} \mathrm{C}$ $\mathrm{yr}^{-1}$ ) of the global annual NPP. Z3 affects global $\triangle$ NEP 


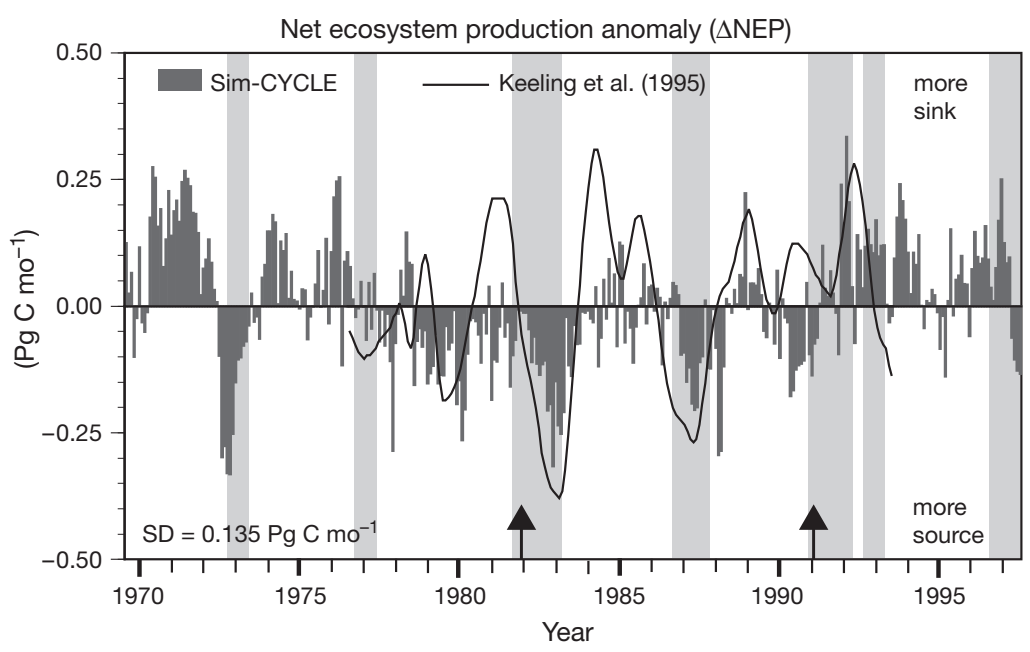

Fig. 8. Anomalies in estimated monthly net ecosystem production $(\triangle \mathrm{NEP})$ derived from Fig. 7. The result of Keeling et al. (1995), derived from the atmospheric $\mathrm{CO}_{2}$ data, is illustrated with a line, for a comparison. Shaded zones and arrows show ENSO events and extremely large volcanic eruptions, respectively coefficient values are also listed for the global analysis, which shows the responsiveness of the biospheric carbon flux to climate anomalies. Apparently, $\triangle \mathrm{AR}$ and $\Delta \mathrm{HR}$ had significant positive correlations with $\Delta \mathrm{TG}$ in all regions; this leads to a high negative correlation of $\triangle \mathrm{NEP}$ with $\triangle \mathrm{TG}$, globally and zonally, even during the growing period. The highest negative correlation between $\triangle \mathrm{TG}$ and $\triangle \mathrm{NEP}$ (standardized correlation coefficient $=-0.919, \mathrm{p}<$ 0.001) emerged in Z3, which is almost completely occupied by tropical evergreen forests (biome 1) and grasslands (biome 8). In these warm biomes, respiration (both $\mathrm{AR}$ and $\mathrm{HR}$ ) had the highest sensitivity to temperature, as expected from the exponential dependence of both types of respiration (see Eqs. 9 \& critically in both directions (either sink or source), except for only 4 (i.e. 1970, 1981, 1992, and 1995) of the 28 years. However, in $3(1970,1981$, and 1995) out 10, Fig. 3). On the other hand, $\triangle$ GPP and $\triangle N P P$ were less sensitive to climatic anomalies. In Z1 and Z3 (Table $5 \mathrm{C}, \mathrm{E}$ ), $\Delta \mathrm{PR}$ and $\Delta \mathrm{SWR}$ had a weak influence on of these 4 years, the biosphere was nearly neutral with respect to the carbon balance (i.e. $\triangle \mathrm{NEP}<\mathrm{SD}$ ). The standard deviations of zonal $\triangle$ NEPs also suggest the outstanding contribution by the tropical zone Z3, such that it had by far the largest SD $\left( \pm 0.66 \mathrm{Pg} \mathrm{C} \mathrm{yr}^{-1}\right)$ among the 4 zones, accounting for over half of the global total.

\subsection{Multiple regression analysis}

Statistical analyses were conducted so as to derive some relationships between climatic anomalies (Fig. 6) and carbon flux anomalies (Table 4, Figs. 7 \& 8). At first, we conducted a multiple regression analysis for the 3 independent climatic variables, $\triangle \mathrm{TG}, \Delta \mathrm{PR}$ and $\triangle \mathrm{SWR}$. Since the term $\Delta \mathrm{TG}$ had high correlations with $\Delta \mathrm{TS}_{10}$ and $\Delta \mathrm{TS}_{200}(\mathrm{p}<0.001)$, we applied it also to $\Delta \mathrm{HR}$. Although PR itself was not used as an input to the simulation experiment, we regarded it as a plain indicator of water availability, rather than $\Delta(\mathrm{AET} / \mathrm{PET})$, which would be contaminated by $\Delta \mathrm{TG}$.

Table 5 shows the standardized correlation coefficients calculated for the global biosphere and the 4 latitudinal zones ( $\mathrm{Z} 1$ to $\mathrm{Z} 4$ ). In Table $5 \mathrm{~A}$, the raw
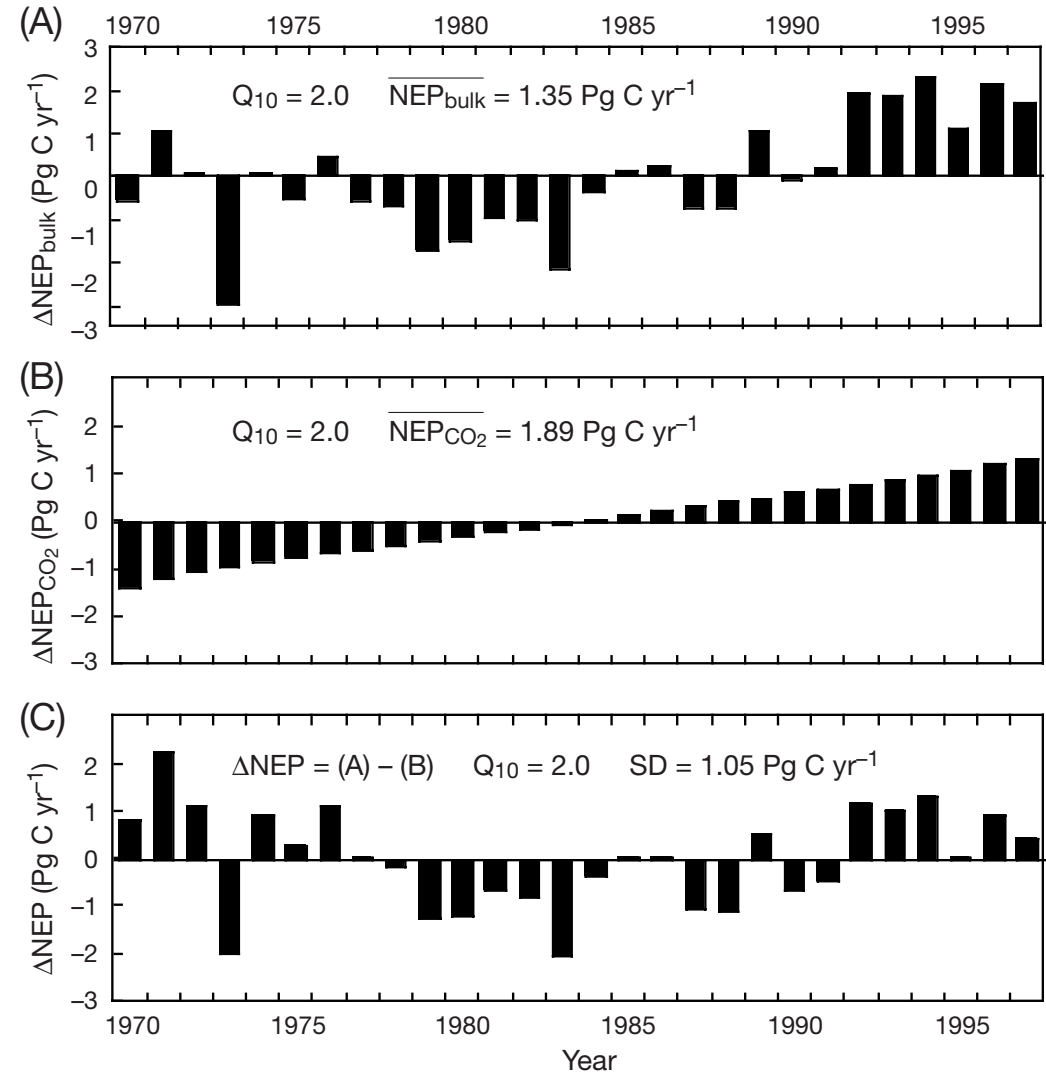

Fig. 9. Annual anomalies in estimated net ecosystem production ( $\triangle \mathrm{NEP})$ : (A) deviation using the actual climate data (see Eq. 2), (B) deviation using the average climate data, representing the $\mathrm{CO}_{2}$ fertilization effect on the carbon budget, and (C) net anomaly $\triangle \mathrm{NEP}$ induced by the climatic variability. The standard $Q_{10}$ value of 2.0 was adopted for AR and HR 

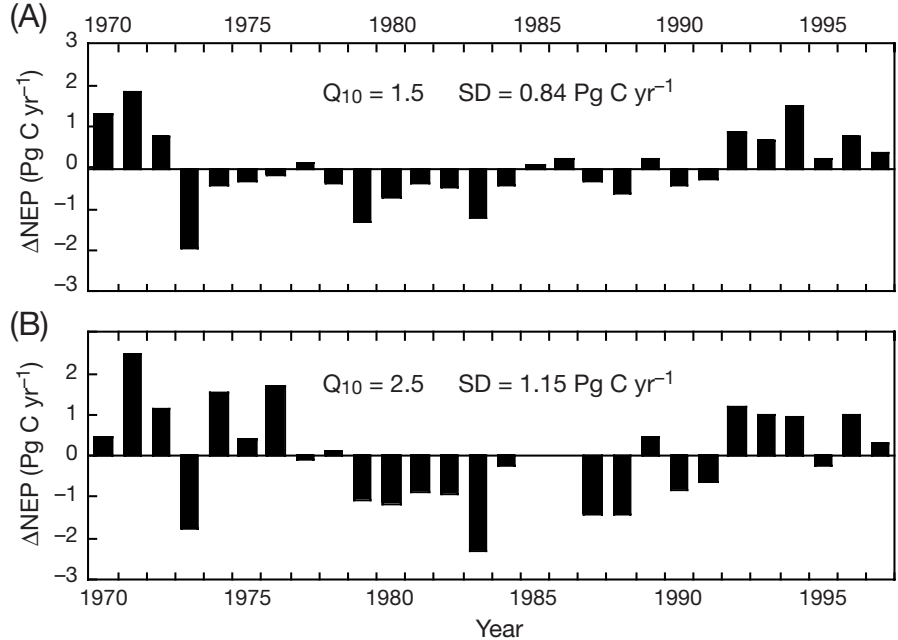

Fig. 10. Annual anomalies in estimated net ecosystem production ( $\triangle \mathrm{NEP}$ ) derived similarly to Fig. 9C, but assuming different temperature sensitivity for AR and HR: (A) $Q_{10}=1.5$ and (B) $Q_{10}=2.5$ while the $\triangle \mathrm{AR}$ and $\Delta \mathrm{HR}$ had stronger correlations $\left(\mathrm{r}^{2}=0.46, \mathrm{p}<0.001\right.$ and $\mathrm{r}^{2}=0.33, \mathrm{p}=0.0015$, respectively) and steeper slopes $\beta_{\mathrm{ann}}=+1.46$ and $+1.57 \mathrm{Pg} \mathrm{C}$ $\mathrm{yr}^{-1}{ }^{\circ} \mathrm{C}^{-1}$, respectively). The $\Delta \mathrm{NPP}$ which is the balance of $\Delta \mathrm{GPP}$ and $\Delta \mathrm{AR}$, had a moderate negative correlation

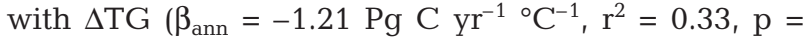
$0.0015)$. Since $\triangle \mathrm{NEP}$ is the balance of $\triangle \mathrm{GPP}, \triangle \mathrm{AR}$, and $\Delta \mathrm{HR}$, it had a considerable negative correlation $\left(\mathrm{r}^{2}=\right.$ $0.38, \mathrm{p}<0.001)$. The highest negative $\beta_{\text {ann }}(-2.69 \mathrm{Pg} \mathrm{C}$ $\mathrm{yr}^{-1}{ }^{\circ} \mathrm{C}^{-1}$ ) between $\triangle \mathrm{TG}$ and $\triangle \mathrm{NEP}$ suggests that a significant amount of carbon would be immediately released from the biosphere to the atmosphere as a result of a small global warming; precipitation anomalies may make deviations from the regression line (Fig. 11E).

\subsubsection{Monthly basis}

A monthly-based analysis was also conducted: slope $\beta_{\text {mon }}\left(\mathrm{Pg} \mathrm{C} \mathrm{mo}{ }^{-1}{ }^{\circ} \mathrm{C}^{-1}\right.$ ) (Fig. 12). $\Delta \mathrm{GPP}$ shows a biannual $\triangle$ GPP and $\triangle N P P$, while $\Delta$ TG had a moderate effect. In Z2, which contains broad areas of arid ecosystems (biomes 8, 9, and 11), higher precipitation resulted in accelerated soil decomposition $(\Delta \mathrm{HR})$, but little change in primary productivity (both $\triangle \mathrm{GPP}$ and $\triangle \mathrm{NPP})$ : thus, $\triangle \mathrm{PR}$ and $\triangle \mathrm{NEP}$ were negatively correlated (Table 5D). The sensitivity of $\Delta$ GPP and $\Delta$ NPP to $\Delta T G$ varied among the latitudinal zones, which differ in habitat temperature conditions and dominant biome type correspondingly. For example, $\triangle$ GPP and $\triangle$ NPP in the cooler zone $\mathrm{Z} 1$ had positive correlations with $\Delta$ TG (Table 5C), while those in the warmer zones Z3 and Z4 had negative ones (Table 5E,F).

\subsection{Linear regression analysis}

Next, we conducted a linear regression analysis to simplify and quantify the relationship between $\Delta \mathrm{TG}$ (the most overriding factor, as shown in Table 5) and carbon flux anomalies, that is, $\Delta F=\beta \cdot \Delta \mathrm{TG}$ ( $\beta$ is the slope).

\subsubsection{Annual basis}

As shown in Fig. 11, the $\triangle$ GPP had little correlation with $\Delta \mathrm{TG}\left(\mathrm{r}^{2}=0.01, \mathrm{p}=0.58\right)$,
Table 4. Estimated annual global carbon flux anomalies, for the case of $Q_{10}=$ 2.0. Zonal values are also listed for $\triangle$ NEP (Z5 was negligible). Exemplified years in text, i.e. 1971, 1983, and 1992, are shaded. The maximum and minimum in each column are given in bold

\begin{tabular}{|c|c|c|c|c|c|c|c|c|c|}
\hline \multirow[t]{3}{*}{ Year } & \multicolumn{9}{|c|}{ Annual carbon flux anomaly $\left(\mathrm{Pg} \mathrm{C} \mathrm{yr}{ }^{-1}\right)$} \\
\hline & \multirow{2}{*}{$\Delta \mathrm{GPP}$} & \multirow{2}{*}{$\Delta \mathrm{AR}$} & \multirow{2}{*}{$\triangle \mathrm{NPP}$} & \multirow{2}{*}{$\Delta \mathrm{HR}$} & \multirow{2}{*}{$\overline{\text { Global }}$} & \multirow[b]{2}{*}{$\mathrm{Z1}$} & \multirow{2}{*}{$\begin{array}{c}\triangle \mathrm{NEP} \\
\mathrm{Z} 2\end{array}$} & \multirow[b]{2}{*}{ Z3 } & \multirow[b]{2}{*}{$\mathrm{Z} 4$} \\
\hline & & & & & & & & & \\
\hline 1970 & 1.00 & 0.74 & 0.26 & -0.55 & 0.82 & 0.02 & 0.23 & 0.21 & 0.35 \\
\hline 1971 & 0.92 & -0.34 & 1.25 & -1.06 & 2.25 & 0.15 & 0.51 & 1.32 & 0.27 \\
\hline 1972 & 0.72 & 0.42 & 0.30 & -0.82 & 1.10 & -0.02 & 0.32 & 0.61 & 0.18 \\
\hline 1973 & -0.46 & 0.23 & -0.69 & 1.34 & -2.00 & -0.19 & -0.29 & -1.04 & -0.48 \\
\hline 1974 & -0.56 & -1.22 & 0.66 & -0.27 & 0.90 & -0.19 & 0.37 & 0.87 & -0.13 \\
\hline 1975 & 0.05 & -0.43 & 0.48 & 0.21 & 0.26 & -0.19 & -0.06 & 0.36 & 0.14 \\
\hline 1976 & -0.41 & -0.90 & 0.48 & -0.71 & 1.13 & -0.16 & 0.37 & 0.67 & 0.26 \\
\hline 1977 & 0.57 & 0.40 & 0.17 & 0.13 & 0.03 & 0.01 & -0.11 & 0.23 & -0.10 \\
\hline 1978 & -0.57 & -0.19 & -0.38 & -0.18 & -0.18 & -0.11 & -0.05 & -0.07 & 0.05 \\
\hline 1979 & 0.11 & 0.45 & -0.34 & 0.90 & -1.28 & -0.09 & 0.01 & -1.06 & -0.13 \\
\hline 1980 & -0.89 & 0.17 & -1.06 & 0.21 & -1.19 & -0.15 & -0.14 & -0.75 & -0.14 \\
\hline 1981 & -0.68 & -0.34 & -0.35 & 0.36 & -0.68 & -0.30 & -0.21 & -0.27 & 0.10 \\
\hline 1982 & -0.34 & 0.04 & -0.39 & 0.43 & -0.83 & -0.01 & -0.24 & -0.62 & 0.04 \\
\hline 1983 & -0.34 & 0.52 & -0.86 & 1.25 & -2.06 & -0.27 & -0.36 & -1.19 & -0.24 \\
\hline 1984 & -0.72 & -0.74 & 0.02 & 0.39 & -0.37 & 0.03 & 0.01 & -0.23 & -0.18 \\
\hline 1985 & -0.50 & -0.40 & -0.10 & -0.11 & 0.03 & 0.08 & -0.17 & 0.25 & -0.13 \\
\hline 1986 & 0.10 & -0.10 & 0.20 & 0.15 & 0.05 & 0.04 & -0.14 & 0.30 & -0.15 \\
\hline 1987 & 0.31 & 0.82 & -0.50 & 0.59 & -1.05 & 0.06 & -0.25 & -0.78 & -0.08 \\
\hline 1988 & -0.19 & 0.27 & -0.46 & 0.69 & -1.11 & -0.18 & -0.30 & -0.62 & -0.01 \\
\hline 1989 & 0.19 & -0.40 & 0.58 & -0.00 & & 0.03 & 0.04 & 0.43 & 0.05 \\
\hline 1990 & 0.45 & 0.61 & -0.16 & & 8 & 0.18 & -0.25 & -0.53 & -0.08 \\
\hline 1991 & -0.00 & 0.23 & -0.23 & & 8 & 0.19 & -0.26 & -0.43 & 0.02 \\
\hline 1992 & -0.11 & -0.46 & 0.35 & -0.82 & & 0.28 & 0.41 & 0.37 & 0.09 \\
\hline 1993 & 0.11 & -0.18 & 0.29 & -0 . & & 0.16 & 0.29 & 0.48 & 0.06 \\
\hline 1994 & 0.76 & 0.20 & 0.55 & -0.76 & & 0.28 & -0.09 & 0.82 & 0.29 \\
\hline 1995 & 0.53 & 0.57 & -0.04 & -0.06 & .01 & 0.15 & 0.03 & -0.33 & 0.16 \\
\hline 1996 & -0.52 & -0.44 & -0.08 & -1.03 & 0.93 & 0.07 & 0.24 & 0.45 & 0.17 \\
\hline 1997 & 0.46 & 0.44 & 0.02 & -0.44 & 0.42 & 0.15 & 0.09 & 0.55 & -0.38 \\
\hline SD & 0.53 & 0.52 & 0.51 & 0.66 & 1.05 & 0.16 & 0.25 & 0.66 & 0.20 \\
\hline
\end{tabular}


Table 5. Standard correlation coefficients between the anomalies in carbon fluxes and the anomalies in climatic factors: surface temperature $(\Delta \mathrm{TG})$, precipitation $(\Delta \mathrm{PR})$, and irradiance $(\Delta \mathrm{SWR})$. To offset the scale difference among the climatic factors, standardized correlation coefficients are listed $\left({ }^{* *} p<0.001 ;{ }^{*} p<0.01\right)$, except for (A), which lists the raw correlation coefficients. Note that TG and SWR are model input data, but PR is not

\begin{tabular}{|c|c|c|c|c|}
\hline & $\begin{array}{l}\Delta \mathrm{TG} \\
\left({ }^{\circ} \mathrm{C}\right)\end{array}$ & $\begin{array}{c}\Delta \mathrm{PR} \\
(\mathrm{mm})\end{array}$ & $\begin{array}{c}\Delta \mathrm{SWR} \\
\left(\mathrm{W} \mathrm{m}^{-2}\right)\end{array}$ & $\mathrm{r}^{2}$ \\
\hline \multicolumn{5}{|c|}{ (A) Global/raw $\left(\mathrm{Pg} \mathrm{C}_{\mathrm{yr}}^{-1}\right)$} \\
\hline$\Delta \mathrm{GPP}$ & 0.359 & -0.013 & -0.066 & \\
\hline$\Delta \mathrm{AR}$ & 1.553 & -0.009 & -0.079 & \\
\hline$\triangle \mathrm{NPP}$ & -1.194 & -0.004 & 0.013 & \\
\hline$\Delta \mathrm{HR}$ & 1.529 & 0.018 & -0.119 & \\
\hline$\triangle \mathrm{NEP}$ & -2.646 & -0.022 & 0.146 & \\
\hline \multicolumn{5}{|c|}{ (B) Global/standardized } \\
\hline$\Delta \mathrm{GPP}$ & 0.161 & -0.516 & -0.075 & 0.146 \\
\hline$\Delta \mathrm{AR}$ & $0.721^{* *}$ & -0.355 & -0.093 & 0.500 \\
\hline$\triangle \mathrm{NPP}$ & $-0.564^{*}$ & -0.181 & 0.016 & 0.284 \\
\hline$\Delta \mathrm{HR}$ & $0.557^{* *}$ & $0.576^{* *}$ & -0.110 & 0.702 \\
\hline$\triangle \mathrm{NEP}$ & $-0.602^{* *}$ & $-0.435^{*}$ & 0.085 & 0.561 \\
\hline \multicolumn{5}{|c|}{ (C) Z1 (N. high)/standardized } \\
\hline$\triangle \mathrm{GPP}$ & $0.654^{* *}$ & -0.368 & -0.245 & 0.541 \\
\hline$\Delta \mathrm{AR}$ & $0.715^{* *}$ & -0.408 & -0.142 & 0.613 \\
\hline$\triangle \mathrm{NPP}$ & $0.594^{*}$ & -0.329 & -0.306 & 0.473 \\
\hline$\Delta \mathrm{HR}$ & $0.689^{* *}$ & 0.320 & -0.089 & 0.667 \\
\hline$\triangle \mathrm{NEP}$ & -0.055 & $-0.755^{*}$ & -0.277 & 0.282 \\
\hline \multicolumn{5}{|c|}{ (D) Z2 (N. middle)/standardized } \\
\hline$\Delta \mathrm{GPP}$ & 0.476 & -0.188 & -0.495 & 0.212 \\
\hline$\Delta \mathrm{AR}$ & $0.843^{* *}$ & -0.100 & -0.085 & 0.630 \\
\hline$\triangle \mathrm{NPP}$ & -0.172 & -0.143 & -0.548 & 0.262 \\
\hline$\Delta \mathrm{HR}$ & $0.538^{* *}$ & $0.526^{* *}$ & 0.186 & 0.577 \\
\hline$\Delta \mathrm{EP}$ & $-0.475^{*}$ & $-0.481^{*}$ & -0.402 & 0.560 \\
\hline \multicolumn{5}{|c|}{ (E) Z3 (Tropical)/standardized } \\
\hline$\Delta \mathrm{GPP}$ & -0.367 & -0.399 & 0.311 & 0.416 \\
\hline$\Delta \mathrm{AR}$ & $0.684^{* *}$ & -0.360 & 0.012 & 0.626 \\
\hline$\triangle \mathrm{NPP}$ & $-0.993^{* *}$ & -0.021 & $0.274^{*}$ & 0.923 \\
\hline$\Delta \mathrm{HR}$ & $0.717^{* *}$ & 0.291 & -0.359 & 0.667 \\
\hline$\triangle \mathrm{NEP}$ & $-0.919^{* *}$ & -0.160 & $0.336^{*}$ & 0.858 \\
\hline \multicolumn{5}{|c|}{ (F) Z4 (S. middle)/standardized } \\
\hline$\Delta \mathrm{GPP}$ & -0.377 & -0.476 & -0.136 & 0.142 \\
\hline$\Delta \mathrm{AR}$ & 0.437 & -0.252 & 0.067 & 0.232 \\
\hline$\triangle \mathrm{NPP}$ & $-0.871^{* *}$ & -0.371 & -0.233 & 0.699 \\
\hline$\Delta \mathrm{HR}$ & $0.338^{*}$ & $0.580^{*}$ & -0.276 & 0.683 \\
\hline$\triangle \mathrm{NEP}$ & $-0.716^{* *}$ & $-0.593^{*}$ & 0.054 & 0.771 \\
\hline
\end{tabular}

Fig. 11. Correlations between anomalies in annual mean global surface temperature $(\triangle \mathrm{TG})$ and anomalies in estimated annual total carbon fluxes $(\mathrm{n}=28$, from 1970 to 1997) (for the case of $Q_{10}=2.0$ ): (A) $\Delta \mathrm{GPP}$, (B) $\Delta \mathrm{AR}$, (C) $\Delta N P P$, (D) $\Delta \mathrm{HR}$, and (E) $\Delta \mathrm{NEP}$. The slope $\left(\beta_{\mathrm{ann}}\right)$ and correlation coefficient $\left(\mathrm{r}^{2}\right)$ of each regression line are given in each panel. The exemplified years in the text are shown: (O) 1971, (匹) 1983, and (ㅁ) 1992
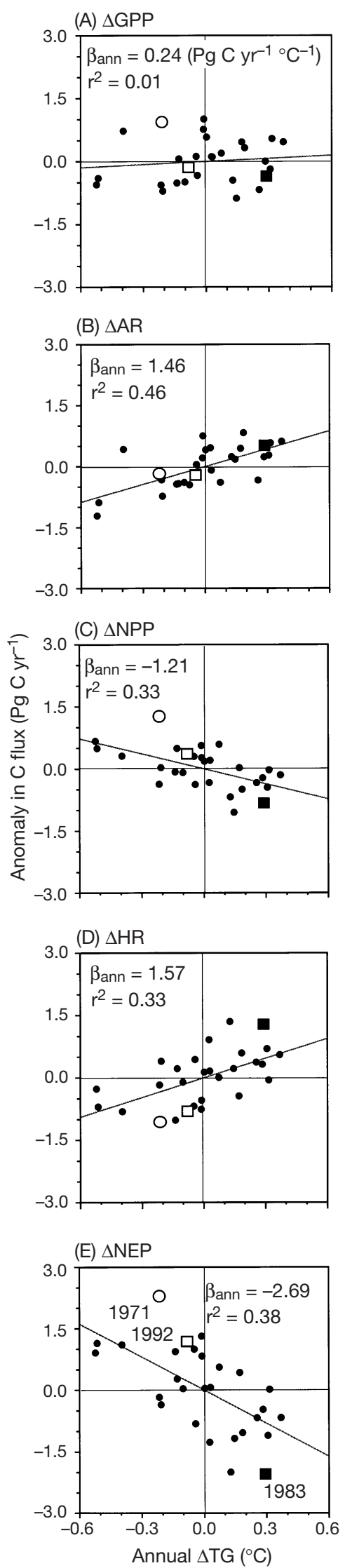


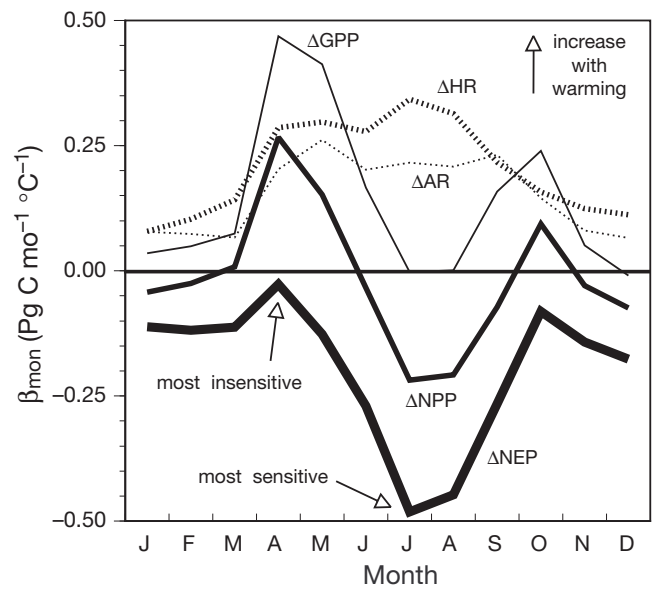

Fig. 12. Seasonal changes in the sensitivity of the estimated monthly global carbon flux anomalies $\left(Q_{10}=2.0\right)$ to the monthly air temperature anomalies, as represented by the slope of linear regressions $\left(\beta_{\mathrm{mon}}\right)$

oscillation with 2 peaks; one shows a strong positive dependence on $\Delta \mathrm{TG}$ in April and May (spring in the northern hemisphere), and the other occurs, to a lesser extent, in September and October (autumn), whereas there is virtually no dependence in July and August (mid-summer in the northern hemisphere) and in November to March (winter). Apparently, the substantial dependencies in spring and autumn are due to the multiple temperature effect on physiological activities (see Eq. 7) and on phenological stimulation (i.e. elongation of growing period). In summer, in contrast, because most ecosystems are largely under their thermal optima, their $\triangle$ GPPs are susceptible to neither physiological nor phenological effects of the temperature fluctuation. $\triangle \mathrm{AR}$ had a positive slope irrespective of season; therefore, $\beta_{\text {mon }}$ of $\Delta$ NPP varied almost in parallel with that of $\triangle \mathrm{GPP}$, i.e. positive in spring and in autumn in the northern hemisphere, and negative in summer and in winter in the northern hemisphere. Similarly, HR had a consistently positive $\beta_{\text {mon }}$ throughout the year. Finally, $\triangle$ NEP had a strong negative slope exceeding $-0.4 \mathrm{Pg} \mathrm{C} \mathrm{mo}{ }^{-1}{ }^{\circ} \mathrm{C}^{-1}$ from June to August (Fig. 12).

We analyzed the spatial heterogeneity as well as monthly change in the relationship between $\Delta \mathrm{TG}$ and $\triangle$ NEP. As shown in Fig. 13, tropical ecosystems in Z3 had negative correlations with $\Delta \mathrm{TG}$ irrespective of seasons, whereas temperate ecosystems in Z2 and boreal ones in Z1 showed a clear seasonal change. In summer and winter, most of them had negative correlations $(\mathrm{r}<0)$, while in spring and autumn, these ecosystems had significantly positive ones $(r>0)$, because a warmer temperature leads to a longer growing period. As a result, global $\triangle$ NEP had a weaker correlation with $\Delta \mathrm{TG}$ in spring and autumn months (e.g. $\mathrm{r}=-0.068$ in April), although locally some ecosystems had substantial responsiveness. These seasonal changes deserve our attention when considering the impacts of climate change on the biospheric carbon budget.

\subsection{Examples of three extreme $\triangle \mathrm{NEP}$ years}

To elucidate the underlying mechanism of large $\triangle$ NEPs, we examine features in 3 interesting years: the largest negative $\triangle \mathrm{NEP}$ in $1983\left(-2.06 \mathrm{Pg} \mathrm{C} \mathrm{yr}^{-1}\right)$, the largest positive $\triangle \mathrm{NEP}$ in $1971\left(+2.25 \mathrm{Pg} \mathrm{C} \mathrm{yr}^{-1}\right)$, and the accidental positive $\triangle \mathrm{NEP}$ in 1992 (a sink year, $+1.14 \mathrm{Pg} \mathrm{C} \mathrm{yr}^{-1}$ ). These years are identified in Fig. 11 and listed in Table 4.

\subsubsection{3: a strong ENSO year}

5.5.1.1. Global maps. Most of the climatic anomalies in 1983 may be relevant to the robust ENSO event, which began in early 1982. Accompanied by a sea-surface temperature rise in the eastern Pacific Ocean, coastal regions of South America had positive $\Delta \mathrm{TG}$ (Fig. 14A). The positive $\Delta \mathrm{TG}$ was also evident in Eurasian regions. From the precipitation anomaly map shown in Fig. 14B, we can find a larger spatial heterogeneity from positive $\triangle \mathrm{PRs}$ in South America and part of Monsoon Asia to negative ones in Africa. Fig. 14C shows a global distribution of $\triangle \mathrm{NEP}$ values which were affected by $\Delta \mathrm{TG}$ and $\Delta \mathrm{PR}$ in 1983 , where many tropical ecosystems and some temperate ecosystems in Europe and North America acted as net carbon sources, while little net carbon sequestration happened in other areas (e.g. a part of South Africa). Especially equatorial South America which had warmer temperatures and high precipitations emitted a large amount of carbon.

5.5.1.2. Zonal distribution of anomalies. Table 4 shows that the carbon emission was especially evident in Z3 $\left(-1.19 \mathrm{Pg} \mathrm{C} \mathrm{yr}^{-1}\right)$, which is the most sensitive to $\Delta \mathrm{TG}$ among the 4 zones. In 1983, Z3 underwent a large positive $\Delta \mathrm{TG}$ of $+0.39^{\circ} \mathrm{C}$ and a moderate negative $\Delta \mathrm{PR}$ of $-12 \mathrm{~mm} \mathrm{yr}^{-1}$. The anomalously high temperature in 1983 was particularly evident from February to July $\left(+0.69^{\circ} \mathrm{C}\right.$, see Fig. $\left.6 \mathrm{~B}\right)$, and it enhanced respiration and decomposition in the tropical ecosystems. We can see from Table 4, summarizing global and zonal anomalies, that not only Z3 but also Z2 had the largest negative $\triangle \mathrm{NEP}\left(-0.36 \mathrm{Pg} \mathrm{C} \mathrm{yr}^{-1}\right)$; $\mathrm{Z} 1$ had the second largest negative (-0.27 $\left.\mathrm{Pg} \mathrm{C} \mathrm{yr}{ }^{-1}\right)$ and $\mathrm{Z} 4$ had the third largest

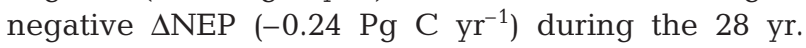
These simultaneous anomalies strongly suggest the impacts of a climate perturbation at the global scale.

5.5.1.3. Biome-specific aspects. Table 6 summarizes such biome-specific features as climate sensitivity and 
Table 6. Biome-specific features in 1983 and 1992: $\Delta \mathrm{TG}, \Delta \mathrm{PR}$, and $\Delta \mathrm{NEP}$, for the case of $Q_{10}=2.0$. The latitudinal zone in which each biome is mainly distributed is given in parenthesis

\begin{tabular}{|c|c|c|c|c|c|c|c|c|c|c|}
\hline \multirow[t]{3}{*}{ Biome } & \multirow{3}{*}{\multicolumn{2}{|c|}{$\begin{array}{c}\beta_{\text {ann }} \text { (slope of regression) } \\
\Delta \mathrm{TG}-\Delta \mathrm{NEP} \quad \Delta \mathrm{PR}-\Delta \mathrm{NEP} \\
\left(\mathrm{Mg} \mathrm{C} \mathrm{ha}^{-1} \quad\left(\mathrm{Mg} \mathrm{C} \mathrm{ha}^{-1}\right.\right. \\
\left.\left.\mathrm{yr}^{-1}{ }^{\circ} \mathrm{C}^{-1}\right) \mathrm{yr}^{-1} 100 \mathrm{~mm}^{-1}\right)\end{array}$}} & \multicolumn{4}{|c|}{1983 (robust ENSO year) } & \multicolumn{4}{|c|}{1992 (post-Mt. Pinatubo-eruption year) } \\
\hline & & & \multirow{2}{*}{$\begin{array}{c}\Delta \mathrm{TG}^{\mathrm{a}} \\
\left({ }^{\circ} \mathrm{C}\right)\end{array}$} & \multirow{2}{*}{$\begin{array}{c}\Delta \mathrm{PR}^{\mathrm{a}} \\
\left(\mathrm{mm} \mathrm{yr}^{-1}\right)\end{array}$} & \multicolumn{2}{|c|}{$\triangle \mathrm{NEP}$} & \multirow{2}{*}{\multicolumn{2}{|c|}{$\begin{array}{l}\Delta \mathrm{TG}^{\mathrm{a}} \Delta \mathrm{PR}^{\mathrm{a}} \\
\left({ }^{\circ} \mathrm{C}\right)\left(\mathrm{mm} \mathrm{yr}^{-1}\right)\end{array}$}} & \multicolumn{2}{|c|}{$\triangle \mathrm{NEP}$} \\
\hline & & & & & $\begin{array}{c}(\mathrm{Mg} \mathrm{C} \\
\left.\mathrm{ha}^{-1} \mathrm{yr}^{-1}\right)\end{array}$ & $\left(\mathrm{Pg} \mathrm{C} \mathrm{yr}^{-1}\right)$ & & & $\begin{array}{c}(\mathrm{MgCC} \\
\left.\mathrm{ha}^{-1} \mathrm{yr}^{-1}\right)\end{array}$ & $\left(\mathrm{Pg} \mathrm{C}_{\mathrm{yr}^{-1}}\right)$ \\
\hline $1(\mathrm{Z} 3)$ & -1.31 & -0.10 & 0.41 & 9.1 & -0.50 & -0.61 & -0.00 & -1.5 & 0.22 & 0.27 \\
\hline $2(\mathrm{Z} 2)$ & -0.71 & -0.15 & 0.09 & 77.2 & -0.26 & -0.17 & -0.13 & -127.3 & 0.21 & 0.14 \\
\hline $3(\mathrm{Z} 2)$ & -0.27 & -0.13 & 0.07 & 73.3 & -0.24 & -0.03 & -0.32 & -54.0 & 0.29 & 0.04 \\
\hline $4(\mathrm{Z} 1)$ & -0.27 & -0.19 & 0.68 & 59.1 & -0.12 & -0.14 & 0.16 & -77.3 & 0.20 & 0.22 \\
\hline 5 (Z1) & 0.01 & -0.23 & 0.46 & 67.2 & -0.19 & -0.18 & 0.23 & -57.5 & 0.18 & 0.17 \\
\hline 6 (Z1) & -0.16 & -0.06 & 0.41 & -31.6 & -0.19 & -0.14 & -0.12 & -1.2 & 0.06 & 0.05 \\
\hline 7 (Z3) & -0.36 & -0.14 & 0.51 & -43.5 & -0.04 & -0.02 & 0.31 & -16.5 & -0.14 & -0.06 \\
\hline 8 (Z3) & -0.27 & -0.16 & 0.32 & 12.5 & -0.18 & -0.49 & -0.05 & -29.6 & 0.07 & 0.20 \\
\hline $9(\mathrm{Z} 2)$ & -0.17 & -0.15 & 0.26 & 33.2 & -0.07 & -0.09 & -0.22 & 19.0 & -0.00 & -0.00 \\
\hline $10(\mathrm{Z} 1)$ & -0.00 & 0.02 & 0.09 & -2.5 & -0.04 & -0.02 & -0.44 & -16.1 & 0.03 & 0.02 \\
\hline 11 (Z2) & -0.00 & -0.01 & -0.15 & -1.6 & -0.00 & -0.002 & -0.42 & 5.3 & -0.00 & -0.007 \\
\hline Cultivated & -0.18 & -0.09 & 0.26 & 28.8 & -0.10 & -0.15 & 0.01 & -48.2 & 0.07 & 0.11 \\
\hline Total $^{\mathrm{b}}$ & -0.27 & -0.20 & 0.30 & 22.4 & -0.16 & -2.06 & -0.07 & -29.1 & 0.09 & 1.14 \\
\hline
\end{tabular}
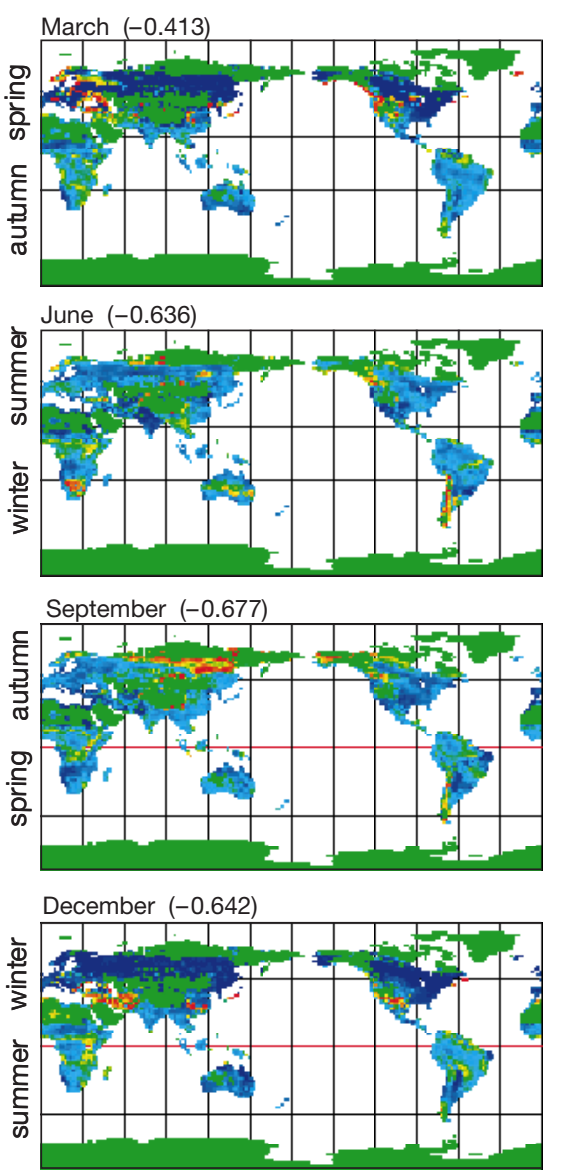

$\Delta \mathrm{TG}-\Delta \mathrm{NEP}$ correlation
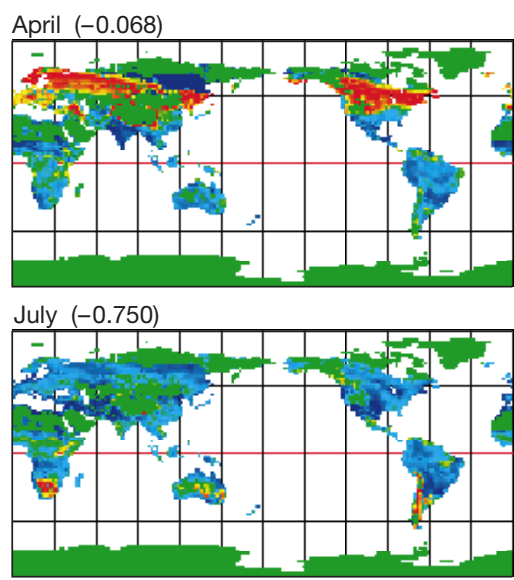

October $(-0.262)$

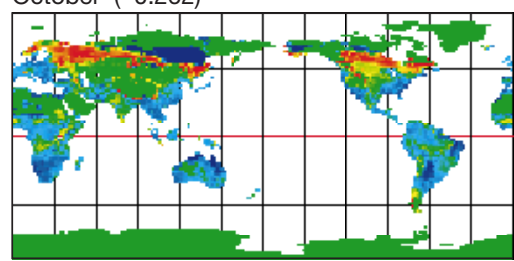

January $(-0.495)$

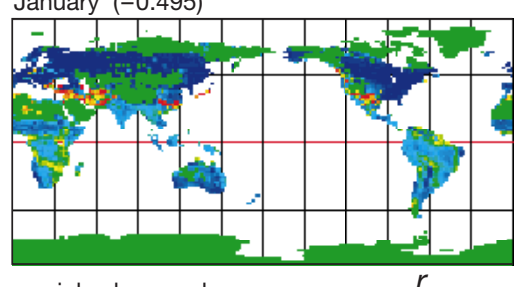

sink when cool
source when warm

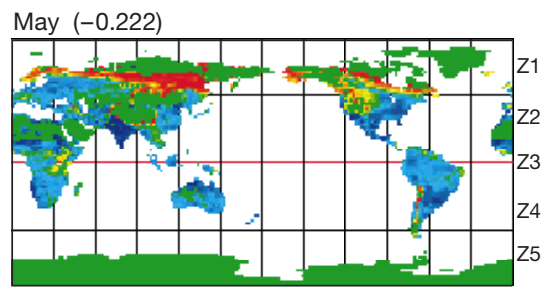

August $(-0.844)$

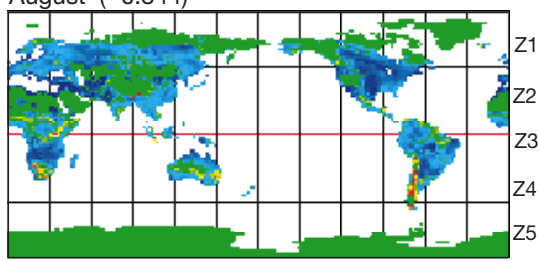

November $(-0.477)$

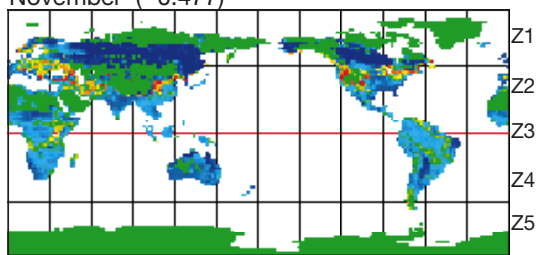

February $(-0.564)$

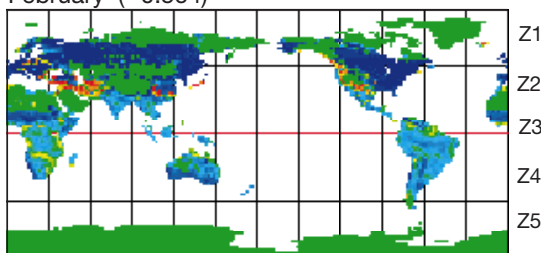

+1 source when coo

Fig. 13. Global maps of the seasonal change in the correlation coefficient (r) between monthly $\Delta \mathrm{TG}$ and $\Delta \mathrm{NEP}\left(Q_{10}=2.0\right)$, from 1970 to 1997. When it has a positive/negative value (in yellow to red/blue), a more active sink or a less active source of carbon is induced by an anomalously warmer/cooler temperature, respectively. The global averages are given in parentheses 

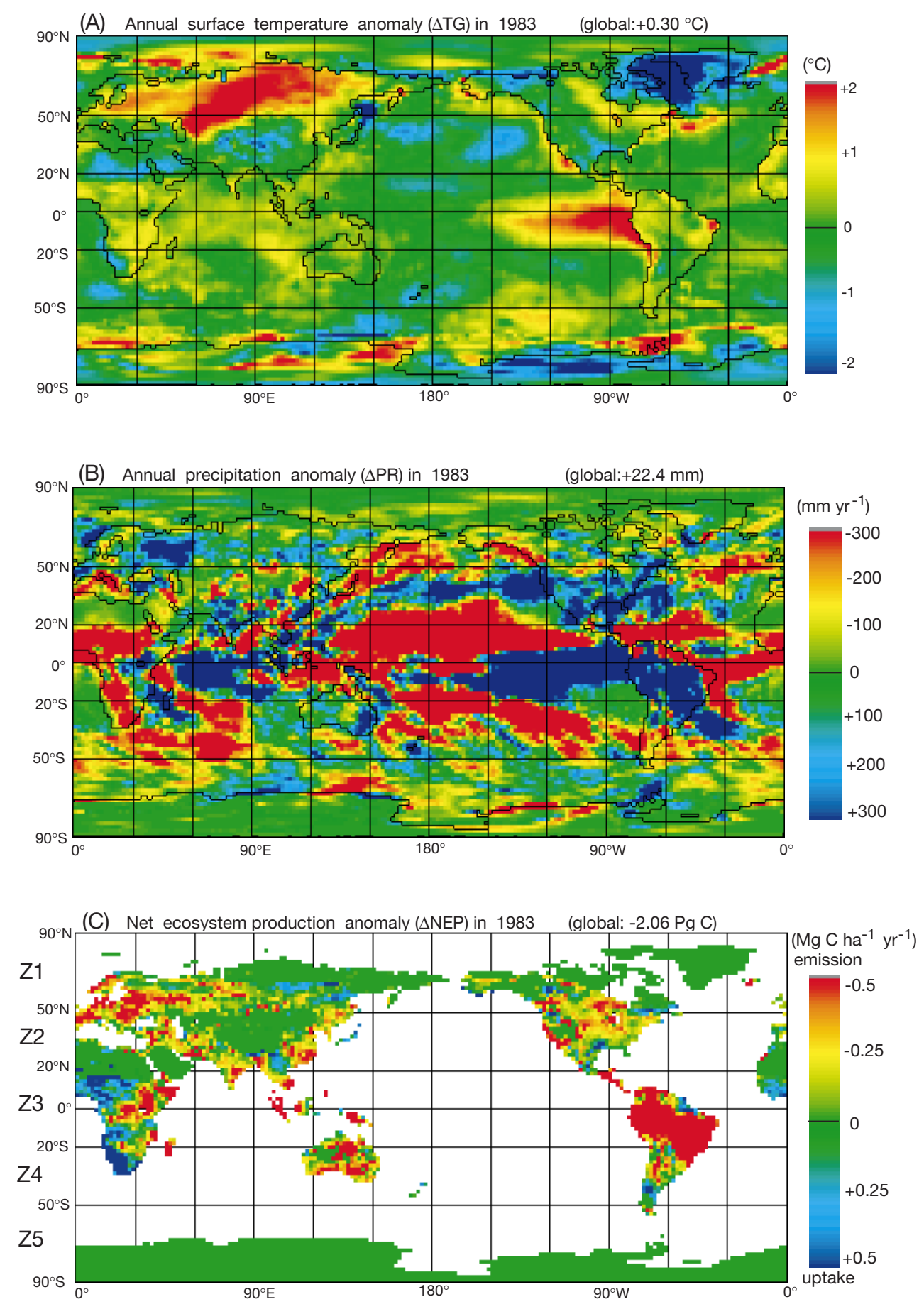

Fig. 14. Global maps of the annual climatic anomalies and resultant net ecosystem carbon balance in 1983, a typical ENSO year. (A) NCEP/NCAR-reanalysis surface temperature $\triangle T$ G, (B) NCEP/NCAR-reanalysis precipitation $\Delta$ PR, and (C) net ecosystem production $\triangle \mathrm{NEP}$ estimated by Sim-CYCLE using $Q_{10}=2.0$

contribution to global $\triangle$ NEPs. In 1983, most biomes had significantly negative $\triangle N E P s$, especially in tropical evergreen forests (biome $1,-0.61 \mathrm{Pg} \mathrm{C} \mathrm{yr}^{-1}$ ) and grass-

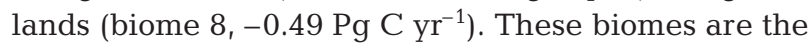

major components in Z3 and are sensitive to $\Delta \mathrm{TG}$ and $\Delta \mathrm{PR}$ (see $\beta_{\mathrm{ann}}$ in Table 6$)$; a positive $\Delta \mathrm{TG}\left(+0.3 \sim 0.4^{\circ} \mathrm{C}\right)$ in these ecosystems is likely to be the principal cause of the global $\triangle$ NEP. This result is consistent with the 

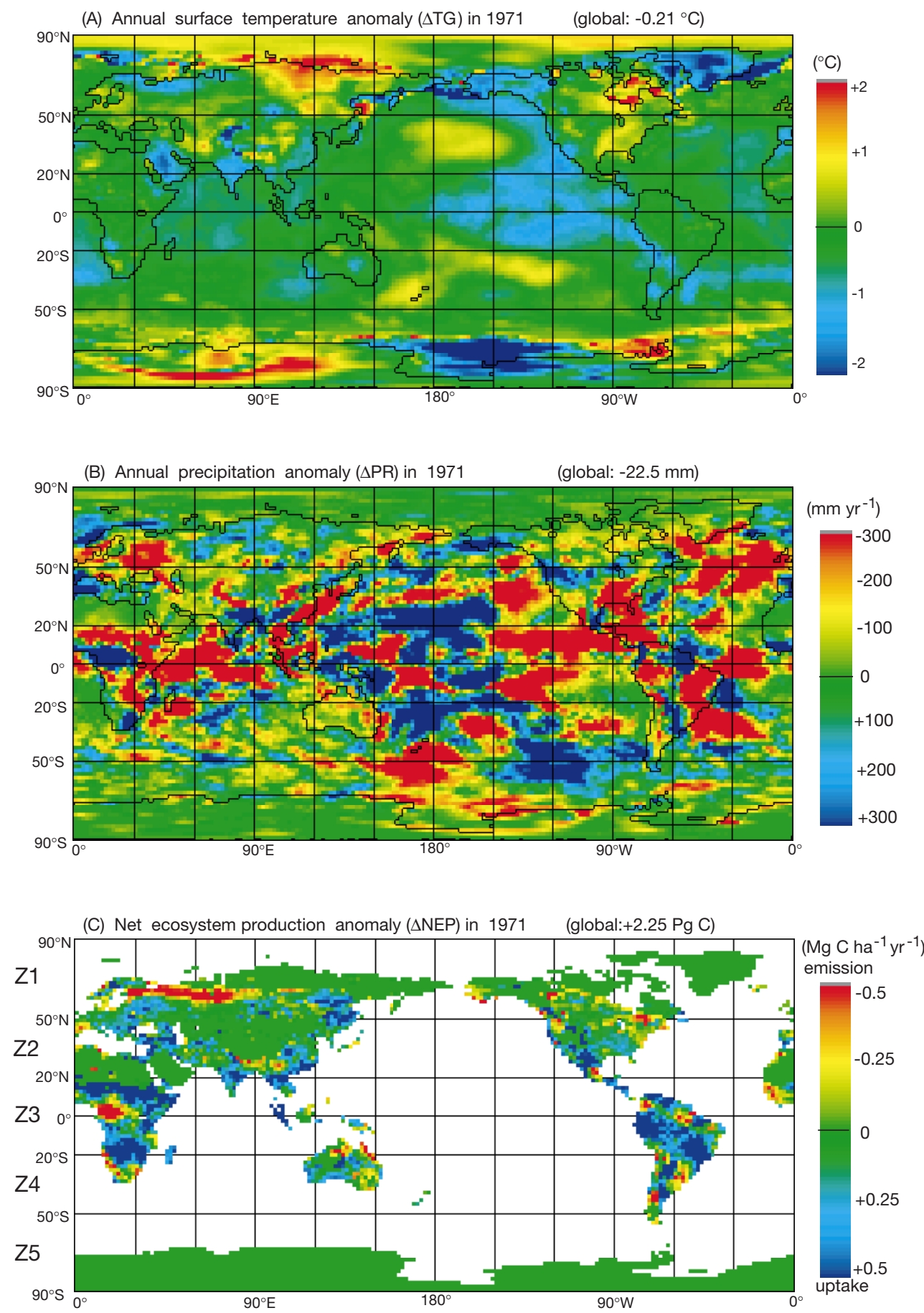

Fig. 15. Global maps of the annual climatic anomalies and resultant net ecosystem carbon balance in 1971, the largest positive $\triangle$ NEP year. (A) NCEP/NCAR-reanalysis surface temperature $\Delta \mathrm{TG}$, (B) NCEP/NCAR-reanalysis precipitation $\Delta \mathrm{PR}$, and (C) net ecosystem production $\triangle$ NEP estimated by Sim-CYCLE using $Q_{10}=2.0$

analysis by Gérard et al. (1999). In contrast, however, savannas (biome 7), which are mainly occupied with $\mathrm{C}_{4}$ grasses, exerted little effect on the global carbon budget, in spite of a large temperature anomaly $\left(+0.5^{\circ} \mathrm{C}\right)$.

\subsubsection{1: the largest positive $\triangle$ NEP year}

5.5.2.1. Global maps. The largest positive global $\triangle \mathrm{NEP}$ took place in $1971(+2.25 \mathrm{Pg} \mathrm{C})$. This is interesting as a 

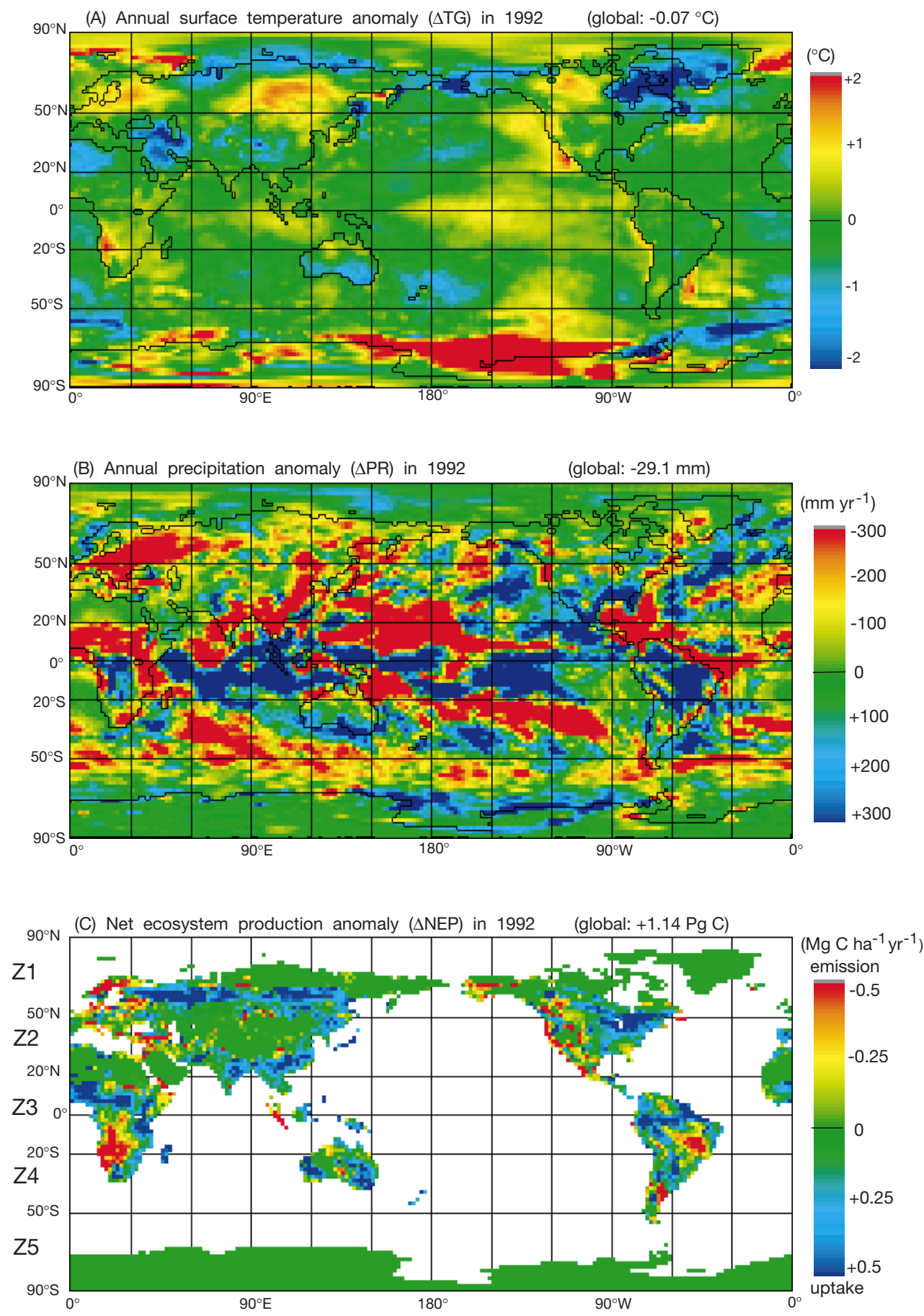

Fig. 16. Global maps of the annual climatic anomalies and resultant net ecosystem carbon balance in 1992, subsequent to the Mt. Pinatubo eruption in June 1991. (A) NCEP/NCAR-reanalysis surface temperature $\Delta T G$, (B) NCEP/NCAR-reanalysis precipitation $\triangle \mathrm{PR}$, and $(\mathrm{C})$ net ecosystem production $\triangle \mathrm{NEP}$ estimated by Sim-CYCLE using $Q_{10}=2.0$

contrast to the largest negative anomaly in 1983. In 1971, a La Niña year, eastern Pacific sea-surface temperature was lower than average (Fig. 15A), and correspondingly global ground surface was cooler than the average by $-0.21^{\circ} \mathrm{C}$ (see Fig. 6B). Although most tropical regions experienced moderate temperatures, they had considerable negative $\Delta \mathrm{PR}$, especially in South America, Africa, and Monsoon Asia (Fig. 15B). Thus, the distribution of carbon anomaly $\triangle \mathrm{NEP}$ (Fig. 15C) seems likely to be related to the negative $\Delta \mathrm{PR}$ rather than $\Delta$ TG. For example, in Africa, the distribution of $\triangle \mathrm{NEP}$ was apparently comparable to that of $\Delta \mathrm{PR}$. 
5.5.2.2. Zonal distribution of anomalies. In 1971, because $\mathrm{Z} 3$ underwent a negative $\Delta \mathrm{TG}\left(-0.34^{\circ} \mathrm{C}\right)$ and a negative $\Delta \mathrm{PR}\left(-47 \mathrm{~mm} \mathrm{yr}^{-1}\right)$, it had the largest positive zonal $\triangle \mathrm{NEP}$ of $+1.32 \mathrm{Pg} \mathrm{C} \mathrm{yr}^{-1}$ (Table 4). Both lower temperature and precipitation reduce carbon emissions by respiration ( $\triangle \mathrm{AR}$ of $-0.34 \mathrm{Pg} \mathrm{C} \mathrm{yr}^{-1}$ ) and decomposition $\left(\Delta \mathrm{HR}\right.$ of $-1.06 \mathrm{Pg} \mathrm{C} \mathrm{\textrm {yr } ^ { - 1 }}$ ), as fully explained by the multiple regression analysis in Section 5.3. Also, note that the year 1971 had the largest positive $\triangle \mathrm{NPP}$ of $+1.25 \mathrm{Pg} \mathrm{C} \mathrm{yr}^{-1}$, due to both positive $\Delta$ GPP and negative $\Delta$ AR (Table 4 ).

\subsubsection{2: after the Mt. Pinatubo eruption}

5.5.3.1. Global maps. Although annual average temperature in 1992 was lower than that in the previous year 1991 by $-0.35^{\circ} \mathrm{C}$ (see Fig. 6B), the temperature anomalies in 1992 (Fig. 16A) seem more gentle than those in 1983. Nevertheless, we can find some cooler (e.g. Middle East and northeastern North America) and warmer (e.g. Siberia and western North America) regions. As shown in Fig. 16C, $\triangle$ NEP values in 1992 in many ecosystems were positive, especially those in South America, North America, Monsoon Asia, and Australia. The large carbon sink in Monsoon Asia seems consistent with (maybe ENSO-induced) negative $\Delta \mathrm{PR}$ (Fig. 16B) which could reduce decomposition (see Table 5).

5.5.3.2. Zonal distribution of anomalies. In 1992, the zone contributing most to $\triangle \mathrm{NEP}$ was the northern middle zone $\mathrm{Z} 2\left(+0.28 \mathrm{Pg} \mathrm{C} \mathrm{yr}^{-1}\right)$, which had a negative $\Delta \mathrm{TG}\left(-0.2^{\circ} \mathrm{C}\right)$ and $\Delta \mathrm{PR}\left(-27.8 \mathrm{~mm} \mathrm{yr}^{-1}\right)$, but insignificant $\triangle \mathrm{PAR}_{\mathrm{SFC}}$. The cooler temperature was especially evident from July to October $\left(-0.79^{\circ} \mathrm{C}\right.$ in $\mathrm{Z} 1$ and $-0.49^{\circ} \mathrm{C}$ in Z2), which was certainly induced by the Mt. Pinatubo eruption in June 1991. As McCormick et al. (1995) summarized, the eruption was so robust that it gave rise to a series of chemical, optical, and climatic ramifications, leading to a global tropospheric cooling in the following few years (see Fig. 6B). Additionally, $\mathrm{PAR}_{\mathrm{SFC}}$ showed little anomaly (see Fig. 6A) in spite of the eruption, because the attenuation of direct radiation could be compensated by increased diffused solar radiation; the latter contains a larger fraction of PAR than direct radiation (Alados-Arboledas et al. 1997). Consequently, lower temperature and precipitation resulted in reduced rates of respiration $(\triangle \mathrm{AR}=-0.46$ $\left.\mathrm{Pg} \mathrm{C} \mathrm{yr}^{-1}\right)$ and decomposition $\left(\Delta \mathrm{HR}=-0.82 \mathrm{Pg} \mathrm{C} \mathrm{yr}^{-1}\right)$.

5.5.3.3. Biome-specific aspects. In 1992, the biome exerting the largest influence on $\triangle \mathrm{NEP}$ was still tropical evergreen forests (+0.27 $\left.\mathrm{Pg} \mathrm{C} \mathrm{yr}^{-1}\right)$. Moreover, temperate deciduous forests (biome 4 ) and temperate and boreal needle-leaved forests (biome 5) in Z1 also made noteworthy positive contributions $(+0.22$ and $+0.17 \mathrm{Pg}$
$\mathrm{C} \mathrm{yr}^{-1}$, respectively). Table 6 lists the annual global $\Delta \mathrm{TG}$ in which cooling is not so evident, but the northern regions had larger negative $\Delta \mathrm{TG}$ by about $-0.4^{\circ} \mathrm{C}$ from April to October, which include the sensitive months (see Fig. 11). Low precipitations (-29 $\mathrm{mm} \mathrm{yr}^{-1}$ ) that could reduce soil moisture affected $\triangle$ NEP by limiting the rate of decomposition.

\section{DISCUSSION}

The multiple and linear regression analyses, shown in Figs. 11 to 13 and Table 5, strongly suggest that the biospheric global carbon budget $\triangle \mathrm{NEP}$ is sensitive to climatic anomalies, primarily in temperature and secondarily in precipitation. Since these outcomes are critically dependent on the characteristics of the simulation model used, we should carefully examine whether the sensitivity is truly due to those of the biosphere or those of Sim-CYCLE, i.e. an artifact. The formulations of carbon dynamics dependent on various environmental factors, such as Eqs. (3) to (14), are simple but would capture a physiological-scale response properly. However, there remain uncertainties about the strength of these sensitivities. Yokota \& Hagihara (1996) observed that the $Q_{10}$ value of woody plant respiration changed seasonally (i.e. larger in winter and smaller in summer), and Knorr \& Heimann (1995) concluded that the most appropriate value of $Q_{10}$ for biospheric respiration (global $\Delta \mathrm{AR}$ and $\Delta \mathrm{HR}$ ) was 1.5 , rather than 2.0 (observed in situ frequently, and adopted by Sim-CYCLE). Our sensitivity analysis also suggests the importance of determining $Q_{10}$ values in appraising the $\mathrm{CO}_{2}$ budget, and the results using $Q_{10}=$ 1.5 may indicate the lower end of biospheric response, and those using $Q_{10}=2.5$ the higher end.

The following facts may allow us to confirm the credence of the model analyses presented in this paper: (1) Sim-CYCLE simulated the features of the contemporary terrestrial carbon budget well and (2) our model analyses agreed satisfactorily with the estimation of $\triangle \mathrm{NEP}$ derived from analyses of atmospheric $\mathrm{CO}_{2}$ and its stable carbon isotopic composition (Keeling et al. 1995, Joos et al. 1999). In fact, the simulated monthly $\triangle$ NEP trend agrees with one by Keeling et al. (1995) (line in Fig. 8), who estimated the net terrestrial and ocean carbon exchanges based on the anomalies in the atmospheric $\mathrm{CO}_{2}$ concentration and its stable carbon isotopic composition. For example, in 1983 and 1988, when they suggested large net terrestrial emissions, Sim-CYCLE also estimated negative $\triangle$ NEPs of comparable magnitude (i.e. 0.2 $\mathrm{Pg} \mathrm{C} \mathrm{mo}^{-1}$ ). In addition, in 1985, 1989, and 1992, when they suggested net sequestrations, Sim-CYCLE also estimated positive $\triangle$ NEPs. 
A point-to-point test is desirable and effective in validating the model analysis, at the ecosystem scale. Using the eddy-correlation method, many researchers have measured net ecosystem energy and gas fluxes under various field conditions (e.g. Goulden et al. 1996). They show that the carbon balance of terrestrial ecosystems has a substantial interannual variation greater than $1 \mathrm{Mg} \mathrm{C} \mathrm{ha}^{-1} \mathrm{yr}^{-1}$ (potentially a few $\mathrm{Pg}$ $\mathrm{C} \mathrm{yr}^{-1}$ at the global scale), reflecting the change in habitat weather conditions (Yamamoto et al. 1999). Although a direct comparison was not carried out, we expect that there is a semi-quantitative agreement between these measurements and our model analysis. Another interesting fact is that these flux-oriented studies often suggest that the observed ecosystems are working as a net carbon sink. Including the $\mathrm{CO}_{2}$ fertilization effect, the Sim-CYCLE simulation also implied a net carbon sequestration into the biosphere (+1.35 Pg $\mathrm{C} \mathrm{yr}^{-1}$ ) of a magnitude comparable to the assumed missing sink.

The Sim-CYCLE analysis could account in part for the anomalously high growth rate of the atmospheric $\mathrm{CO}_{2}$ concentration after the outbreak of ENSO events (Bacastow 1976, Keeling et al. 1989). Probably, the effect of ENSO events is considerably relevant to the largest $\triangle \mathrm{NEP}$ in the tropical zone Z3 (see Table 5). For example, after the ENSO episodes in 1983 and 1987, Sim-CYCLE estimated larger carbon emissions from the biosphere (see Fig. 9), and conversely in 1989 after La Niña it estimated larger carbon uptakes, so that the atmospheric $\mathrm{CO}_{2}$ had corresponding anomalies. However, there remain uncertainties with respect to the effect of ENSO events on ecosystem carbon budget. For example, the Sim-CYCLE analysis does not account for the observed time-lags in the atmospheric $\mathrm{CO}_{2}$ behind the anomalies in air temperature (Keeling et al. 1989) and in Southern Oscillation Index (Bacastow 1976, Rayner et al. 1999). Because of the time-lag, most of the impacts of the huge ENSO event in 1997 would emerge in 1998, which is not included here. The $\mathrm{CO}_{2}$ anomaly in relation to the ENSO events would essentially include oceanic processes, such as the interruption of the upwelling of $\mathrm{CO}_{2}$-rich deep water (Dettinger \& Ghil 1998, Feely et al. 1999); the oceanic carbon budget has a variability comparable $(\mathrm{SD}=$ 1.0 Pg C yr-1; Joos \& Bruno 1998) to the terrestrial one

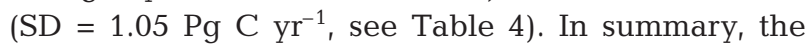
terrestrial mechanism had a partial contribution to the observed $\mathrm{CO}_{2}$ anomaly, but to determine its magnitude will require more information and research.

In relation to the Mt. Pinatubo carbon anomaly, we hypothesize that the large $\triangle$ NEP in $1992(+1.14 \mathrm{Pg} \mathrm{C}$ $\mathrm{yr}^{-1}$ ) was brought about by a series of causal relationships after the Mt. Pinatubo eruption in June 1991 (McCormick et al. 1995, Jones \& Kelly 1996, Alados-
Alboledas et al. 1997). The estimated $\triangle$ NEP in 1992 agrees satisfactorily with the atmospheric $\mathrm{CO}_{2}$-based value (i.e. +1.0 to $2.5 \mathrm{Pg} \mathrm{C} \mathrm{yr}^{-1}$ by Keeling et al. 1995), although a contradictory estimation was presented by Francey et al. (1995). We acknowledge indeed that the Mt. Pinatubo carbon anomaly was not a simple phenomenon as hypothesized here, because the oceanic processes might be induced as suggested by Sarmiento (1993). Nevertheless, there are several lines of sound evidence supporting the conclusion that the biospheric processes should make a substantial contribution to the anomaly in the atmospheric $\mathrm{CO}_{2}$ concentration. For example, Ciais et al. (1995) also estimated a net carbon uptake in the northern middle to high latitudinal ecosystems in 1992 using the SiB2 model, but their estimation $(+3.5 \mathrm{Pg} \mathrm{C})$ is much larger than ours (+0.69 Pg C, in $\mathrm{Z1}$ and $\mathrm{Z2}$ ).

On the role of the terrestrial biosphere in the interannual carbon budget, there are several points demanding further consideration and modification to modelling research, including our analysis. Since Dai \& Fung (1993) and Kaduk \& Heimann (1994) studied the annual carbon budget of terrestrial ecosystems with empirical models, the issue has attracted the attentions of modelers. For example, Kindermann et al. (1996) applied the Frankfurt Biosphere Model to interannual change from 1980 to 1992, and they found features similar to those described in this paper. However, they ascribed the interannual change in $\triangle \mathrm{NEP}$ mainly to the change in $\triangle \mathrm{NPP}$ rather than $\Delta \mathrm{HR}$. Myneni et al. (1997) analyzed the temporal change in remotely sensed NDVI (normalized difference vegetation index), and showed that the biospheric carbon budget is sensitive to the interannual change in temperature. They concluded that the warmer climate during recent years has led to a prolonged growing period of vegetation and consequently increased production. Our model analysis is nearly coincident with their satellite-based analysis, e.g. in 1983 negative anomalies were estimated in both observed NDVI and model-based NPP. However, we cannot account for the significantly positive anomalies in NDVI in 1989 to 1990, when Sim-CYCLE estimated only little $\triangle$ NPP. Braswell et al. (1997) analyzed the correspondence between $\triangle \mathrm{NEP}$ and $\Delta \mathrm{TG}$, and suggested a response time-lag of approximately 2 yr. Although they attributed the time-lag to an undetermined underground process, we did not find out the nature of the process in this paper, in which responses at the physiological level were mainly addressed. Applying a process-based model (Terrestrial Ecosystem Model), Tian et al. (1998) simulated the carbon budget of the Amazon Basin from 1980 to 1994, and suggested that the regional $\triangle \mathrm{NEP}$ varied substantially during this period, and that it was sensitive to temperature and soil water change. The model analysis presented in our 
paper is one of the few studies that analyzed the interannual time-series of carbon budget anomalies with a mechanistic model and accurate climate dataset.

The climate sensitivity of the biospheric carbon budget may have an important implication with respect to the impact of anticipated global change (IPCC 1996). According to the estimated negative $\Delta \mathrm{TG}-\Delta \mathrm{NEP}$ relationship (Fig. 11E), global warming is likely to lead to net release of carbon, i.e. the biotic positive feedback to the prescribed warming, at least in the short term. However, our model analyses revealed that the $\Delta$ TG- $\Delta$ NEP relationship changes zonally (Table 5) and seasonally (Figs. $12 \& 13$ ), and that the precipitation anomaly could play an important role in the carbon budget in northern high and middle latitudinal zones (Table 5). Explicitly, our result suggests that we should develop a finer model and perform a series of sensitivity analyses, so that we are able to quantify the feedback effect. For example, Sim-CYCLE does not yet contain the nutrient dynamics in the soil, which may have a close linkage with carbon dynamics and also be sensitive to temperature (McGuire et al. 1997). In addition, since we focused on the effects of climatic perturbations in this study, the biospheric carbon budget was assumed to be at equilibrium at the beginning of the simulation. Then, the additional human land-use change after 1970 and the carbon emission accompanied with deforestation were not included. In the strong ENSO events in 1983 and 1997, broad areas of tropical forests in Southeast Asia suffered from fire due to drought promoting biomass inflammability. However, we know little about how much carbon was lost from the burned forests, and how much was restored by the following successional regrowth. As Schimel et al. (1997) stated, we should take care that disturbance processes (both natural and anthropogenic) are essential parts of ecosystem dynamics and biogeochemistry, especially when we appraise the biotic feedbacks under future global change. An improved model and simulation result covering a longer term will be presented in our forthcoming research.

Acknowledgements. This study was financially supported, in part, by a Grant-in-Aid from the Ministry of Education, Science and Culture, Japan (10144204 to T.O.), and a Grantin-Aid of the Research Fellowships of the Japan Society for the Promotion of Science for Young Scientists (to A.I.). The biome dataset was supplied by the United Nations Environment Programme/Global Resource Information Database (UNEP/GRID), Tsukuba, Japan. The climate dataset was supplied by the US National Centers for Environmental Prediction, and the US National Center for Atmospheric Research. We thank Dr R. Weisburd, University of Tsukuba, for his assistance in preparing this manuscript. This paper is dedicated to the late Emeritus Professor M. Monsi, University of Tokyo, who established the dry-matter production theory in plant ecology.

\section{LITERATURE CITED}

Alados-Arboledas L, Olmo FJ, Ohvail HO, Teral T, Arak M, Teral K (1997) Evolution of solar radiative effects of Mount Pinatubo at ground level. Tellus 49B:190-198

Amthor JS (1994) Plant respiratory responses to the environmental and their effects on the carbon balance. In: Wilkinson RE (ed) Plant-environment interactions. Marcel Dekker Inc, New York, p 501-554

Bacastow RB (1976) Modulation of atmospheric carbon dioxide by the Southern Oscillation. Nature 261:116-118

Bolin B, Degens ET, Duvigneaud P, Kempe S (1979) The global biogeochemical carbon cycle. In: Bolin B, Degens ET, Kempe S, Ketner P (eds) The global carbon cycle, SCOPE 13. John Wiley \& Sons, New York, p 1-53

Braswell BH, Schimel DS, Linder E, Moore B III (1997) The response of global terrestrial ecosystems to interannual temperature variability. Science 278:870-872

Ciais P, Tans PP, Trolier M, White JWC, Francey RJ (1995) A large Northern Hemisphere terrestrial $\mathrm{CO}_{2}$ sink indicated by the ${ }^{13} \mathrm{C} /{ }^{12} \mathrm{C}$ ratio of atmospheric $\mathrm{CO}_{2}$. Science 269: 1098-1102

Collatz GJ, Berry JA, Clark JS (1998) Effects of climate and atmospheric $\mathrm{CO}_{2}$ partial pressure on the global distribution of $\mathrm{C}_{4}$ grasses: present, past, and future. Oecologia 114:441-454

Cramer W, Kicklighter DW, Bondeau A, Moore BI, Churkina G, Ruimy A, Scloss A, the Participants of 'Potsdam '95' (1997) Comparing global models of terrestrial net primary productivity (NPP): overview and key results. Potsdam Institute for Climate Impact Research, Potsdam

Curtis PS, Wang X (1998) A meta-analysis of elevated $\mathrm{CO}_{2}$ effects on woody plant mass, form, and physiology. Oecologia 113:299-313

Dai A, Fung IY (1993) Can climate variability contribute to the 'missing' $\mathrm{CO}_{2}$ sink? Global Biogeochem Cycles 7:599-609

Dettinger MD, Ghil M (1998) Seasonal and interannual variations of atmospheric $\mathrm{CO}_{2}$ and climate. Tellus 50B:1-24

Ehleringer J, Björkman O (1977) Quantum yields for $\mathrm{CO}_{2}$ uptake in $\mathrm{C}_{3}$ and $\mathrm{C}_{4}$ plants. Plant Physiol 59:86-90

Ehleringer JR, Cerling TE, Helliker BR (1997) $\mathrm{C}_{4}$ photosynthesis, atmospheric $\mathrm{CO}_{2}$, and climate. Oecologia 112: 285-299

Feeley RA, Wanninkhof R, Takahashi T, Tans P (1999) Influence of El Niño on the equatorial Pacific contribution to atmospheric $\mathrm{CO}_{2}$ accumulation. Nature 398:597-601

Fitter AH, Hay RKM (1981) Environmental physiology of plants. Academic Press, San Diego

Francey RJ, Tans PP, Allison CE, Enting IG, White JWC, Trolier M (1995) Changes in oceanic and terrestrial carbon uptake since 1982. Nature 373:326-330

Gérard JC, Nemry B, François LM, Warnant P (1999) The interannual change of atmospheric $\mathrm{CO}_{2}$ : contribution of subtropical ecosystems? Geophys Res Lett 26:243-246

Goulden ML, Munger JW, Fan SM, Daube BC, Wofsy SC (1996) Exchange of carbon dioxide by a deciduous forest: response to interannual climate variability. Science 271: $1576-1578$

Halpert MS, Ropelewski CF (1992) Surface temperature patterns associated with the southern oscillation. J Clim 5:577-593

Houghton RA, Davidson EA, Woodwell GM (1998) Missing sinks, feedbacks, and understanding the role of terrestrial ecosystems in the global carbon balance. Global Biogeochem Cycles 12:25-34

Intergovernmental Panel on Climate Change (IPCC) (1996) Climate change 1995: the science of climate change. 
Houghton JT, Filho LGM, Bruce J, Lee H, Callander BA, Haites E, Harris N, Maskell K (eds). Cambridge University Press, Cambridge

Jones HG (1992) Plants and microclimate, 2nd edn. Cambridge University Press, Cambridge

Jones PD, Kelly PM (1996) The effect of tropical explosive volcanic eruptions on surface air temperature. In: Fiocco G, Fua D, Visconti G (eds) The Mount Pinatubo eruption: effects on the atmosphere and climate. Springer, Berlin, p 95-111

Joos F, Bruno M (1998) Long-term variability of the terrestrial and oceanic carbon sinks and the budgets of the carbon isotopes ${ }^{13} \mathrm{C}$ and ${ }^{14} \mathrm{C}$. Global Biogeochem Cycles 12: 277-295

Joos F, Meyer R, Bruno M, Leuenberger M (1999) The variability in the carbon sinks as reconstructed for the last 1000 years. Geophys Res Lett 26:1437-1440

Kaduk J, Heimann M (1994) The climate sensitivity of the Osnabrück Biosphere Model on the ENSO time scale. Ecol Model 75:239-256

Kalnay E, Kanamitsu M, Kistler R, Collins W, Deaven D, Gandin L, Iredell M, Saha S, White G, Woollen J, Zhu Y, Chelliah M, Ebisuzaki W, Higgins W, Janowiak J, Mo KC, Ropelewski C, Wang J, Leetmaa A, Reynolds R, Jenne R, Joseph D (1996) The NCEP/NCAR 40-year reanalysis project. Bull Am Meteorol Soc 77:437-471

Keeling CD, Bacastow RB, Carter AF, Piper SC, Whorf TP, Heimann M, Mook WG, Roeloffzen H (1989) A threedimensional model of atmospheric $\mathrm{CO}_{2}$ transport based on observed winds. 1. Analysis of observational data. Geophys Monogr 55:165-236

Keeling CD, Whorf TP, Wahlen M, van der Plicht J (1995) Interannual extremes in the rate of atmospheric carbon dioxide since 1980. Nature 375:666-670

Kindermann J, Würth G, Kohlmaier GH, Badeck FW (1996) Interannual variation of carbon exchange fluxes in terrestrial ecosystems. Global Biogeochem Cycles 10:737-755

Knorr W, Heimann M (1995) Impact of drought stress and other factors on seasonal land biosphere $\mathrm{CO}_{2}$ exchange studies through an atmospheric tracer transport model. Tellus 47B:471-489

Kohlmaier GH, Bröhl H, Sire EO, Plöchl M, Revelle R (1987) Modelling stimulation of plants and ecosystem response to present levels of excess atmospheric $\mathrm{CO}_{2}$. Tellus 39B: $155-170$

Kuroiwa S (1966) Dry matter production of plants. In: Kawanabe $\mathrm{H}$ (ed) Ecology and evolution. Iwanami Shoten, Tokyo, p 71-100 (in Japanese)

Larcher W (1995) Physiological plant ecology: ecophysiology and stress physiology of functional groups. Springer, Berlin

Leemans R, Cramer WP (1991) The IIASA database for mean monthly values of temperature, precipitation and cloudiness of a global terrestrial grid. IIASA, Laxenburg

Lieth $H$ (1975) Modeling the primary productivity of the world. In: Lieth H, Whittaker RH (eds) Primary productivity of the biosphere. Springer, Berlin, p 237-263

Maisongrande P, Ruimy A, Dedieu G, Saugier B (1995) Monitoring seasonal and interannual variations of gross primary productivity, net primary productivity and net ecosystem productivity using a diagnostic model and remotely-sensed data. Tellus 47B:178-190

Manabe S, Wetherald RT (1987) Large-scale changes of soil wetness induced by an increase in atmospheric carbon dioxide. J Atmos Sci 44:1211-1235

Matthews E (1983) Global vegetation and land use: new high resolution data bases for climate studies. J Clim Appl Meteorol 22:474-487
McCormick MP, Thomason LW, Trepte CR (1995) Atmospheric effects of the Mt Pinatubo eruption. Nature 373: 399-404

McGuire AD, Melillo JM, Kicklighter DW, Pan Y, Xiao X, Helfrich J, Moore B III, Vörösmarty CJ, Schloss AL (1997) Equilibrium responses of global net primary production and carbon storage to doubled atmospheric carbon dioxide: sensitivity to changes in vegetation nitrogen content. Global Biogeochem Cycles 11:173-189

Meentemeyer V (1984) The geography of organic decomposition rates. Ann Assoc Am Geogr 74:551-560

Melillo JM, Prentice IC, Farquhar GD, Schulze ED, Sala OE (1996) Terrestrial biotic responses to environmental change and feedbacks to climate. In: Houghton JT, Meira Filho LG, Callander BA, Harris N, Kattenberg A, Maskell K (eds) Climate change 1995: the science of climate change. Cambridge University Press, Cambridge, p 445-482

Monsi M (1960) Dry-matter reproduction in plants. I. Schemata of dry-matter reproduction. Bot Mag 73:81-90

Monsi M, Saeki T (1953) Über den Lichtfaktor in den Pflanzengesellschaften und seine Bedeutung für die Stoffproduktion. Jpn J Bot 14:22-52

Myneni RB, Keeling CD, Tucker CJ, Asrar G, Nemani RR (1997) Increased plant growth in the northern high latitudes from 1981 to 1991. Nature 386:698-702

New M, Hulme M, Jones P (1999) Representing twentiethcentury space-time climate variability. Part 1: development of a 1961-1990 mean monthly terrestrial climatology. J Clim 12:829-856

Oikawa T (1985) Simulation of forest carbon dynamics based on dry-matter production model. 1. Fundamental model structure of a tropical rainforest ecosystem. Bot Mag 98: $225-238$

Oikawa T (1995) A simulation study of grassland carbon dynamics as influenced by atmospheric $\mathrm{CO}_{2}$ concentration. In: Murai S (ed) Toward global planning of sustainable use of the earth: development of global eco-engineering. Elsevier, Amsterdam, p 97-112

Oikawa T (1998) Modeling carbon dynamics of a lucidophyll forest under monsoon climates. Global Environ Res 1: 25-33

Poorter H (1993) Interspecific variation in the growth response of plants to an elevated ambient $\mathrm{CO}_{2}$ concentration. Vegetatio 104/105:77-97

Potter CS, Klooster S, Brooks V (1999) Interannual variability in terrestrial net primary production: exploration of trends and controls on regional to global scales. Ecosystems 2: $36-48$

Raich JW, Schlesinger WH (1992) The global carbon dioxide flux in soil respiration and its relationship to vegetation and climate. Tellus 44B:81-99

Raich JW, Rastetter EB, Melillo JM, Kicklighter DW, Grace AL, Moore B III, Vörösmarty CJ (1991) Potential net primary productivity in South America: application of a global model. Ecol Appl 1:399-429

Rayner PJ, Law RM (1999) The interannual variability of the global carbon cycle. Tellus 51B:210-212

Rayner PJ, Law RM, Dargaville R (1999) The relationship between tropical $\mathrm{CO}_{2}$ fluxes and the El Niño Southern Oscillation. Geophys Res Lett 26:493-496

Robock A, Mao J (1995) The volcanic signal in surface temperature observations. J Clim 8:1086-1103

Ropelewski CF, Halpert MS (1987) Global and regional precipitation patterns associated with the El Niño/Southern Oscillation. Mon Weather Rev 115:1606-1626

Ruimy A, Jarvis PG, Baldocchi DD, Saugier B (1995) $\mathrm{CO}_{2}$ fluxes over plant canopies and solar radiation: a review. 
Adv Ecol Res 26:1-68

Ryan MG (1991) Effects of climate change on plant respiration. Ecol Appl 1:157-167

Sage RF, Wedin DA, Li M (1999) The biogeography of $\mathrm{C}_{4}$ photosynthesis: patterns and controlling factors. In: Sage RF, Monson RK (eds) $\mathrm{C}_{4}$ plant biology. Academic Press, San Diego, p 313-373

Sarmiento JL (1993) Atmospheric $\mathrm{CO}_{2}$ stalled. Nature 365: 697-698

Schimel DS, VEMAP participants, Braswell BH (1997) Continental scale variability in ecosystem processes: models, data, and the role of disturbance. Ecol Monogr 67:251-271

Teeri JA, Stowe LG (1976) Climatic patterns and the distribution of $\mathrm{C}_{4}$ grasses in North America. Oecologia 23:1-12

Tian H, Melillo JM, Kicklighter DW, McGuire AD, Helfrich JVKI, Moore BI, Vörösmarty CJ (1998) Effect of interannual climate variability on carbon storage in Amazonian ecosystems. Nature 396:664-667

Whittaker RH (1975) Communities and ecosystems. Macmillan Company, New York

Witcamp M (1966) Decomposition of leaf litter in relation to environment, microflora, and microbial respiration. Ecology

Editorial responsibility: Gerd Esser,

Gießen, Germany
47:194-201

Wittenberg U, Heimann M, Esser G, McGuire AD, Sauf W (1998) On the influence of biomass burning on the seasonal $\mathrm{CO}_{2}$ signal as observed at monitoring stations. Global Biogeochem Cycle 12:531-544

World Data Centre for Greenhouse Gases (WDCGG) (1998) WMO WDCGG Data Report (WDCGG No. 17). Japan Meteorological Agency, Tokyo

Wullschleger SD, Post WM, King AW (1995) On the potential for a $\mathrm{CO}_{2}$ fertilization effect in forests: estimates of the biotic growth factor based on 58 controlled-exposure studies. In: Woodwell GM, Mackenzie FT (eds) Biotic feedbacks in the global climatic system: will warming feed the warming? Oxford University Press, Oxford, p 85-107

Yamamoto S, Murayama S, Saigusa N, Kondo H (1999) Seasonal and inter-annual variability of $\mathrm{CO}_{2}$ flux between a temperate forest and the atmosphere in Japan. Tellus 51B: 402-413

Yokota T, Hagihara A (1996) Seasonal change in the temperature coefficient $Q_{10}$ for respiration of field grown hinoki cypress (Chamaecyparis obtusa) trees. J For Res 1: 165-168

Submitted: September 21, 1999; Accepted: March 10, 2000 Proofs received from author(s): August 14, 2000 